\title{
Peixes da Estação Ecológica Serra Geral do Tocantins, bacias dos Rios Tocantins e São Francisco, com observações sobre as implicações biogeográficas das “águas emendadas” dos Rios Sapão e Galheiros
}

\author{
Flávio César Thadeo de Lima $^{1,2}$ \& Rodrigo Antunes Caires ${ }^{1}$ \\ ${ }^{1}$ Museu de Zoologia, Universidade de São Paulo - USP, CP 42494, CEP 04299-970, São Paulo - SP, Brasil \\ ${ }^{2}$ Autor para correspondência: Flávio César Thadeo Lima, e-mail: fctlima@gmail.com
}

LIMA, F.C.T. \& CAIRES, R.A. Fishes from the Serra Geral do Tocantins Ecological Station, Rio Tocantins and Rio São Francisco basins, with remarks on the biogeographical implications of the common headwater between the Rio Sapão and Rio Galheiros. Biota Neotrop. 11(1): http://www.biotaneotropica.org.br/v11n1/ en/abstract?article+bn03411012011.

\begin{abstract}
A preliminary ichthyofaunistic survey conducted at the Serra Geral de Tocantins Ecological Station (Southeastern Tocantins and Northwest Bahia States, central Brazil) is presented. This Ecological Station is situated at the water divide between the Rio São Francisco basin (Rio Sapão) and Rio Tocantins (Rio Novo, Rio Balsas, and Rio Manuel Alves da Natividade basins). A common headwater ("água emendada") between the Rio Sapão and the Rio Galheiros (the latter a tributary of the Rio Novo) lies within the station boundaries and is considered in the literature as a potential area of faunistic interchange between the Rio São Francisco and the Rio Tocantins basins. Thirty-five fish species were recorded within the Serra Geral de Tocantins Ecological Station and at its immediate surroundings, some of which unknown to science and potentially endemic to the area. A total of 111 fish species were regionally recorded (i.e., including fish species recorded at downstream stretches of the Rio Sapão and Rio Novo/do Sono, below the ecological station). The cichlid Cichlasoma sanctifranciscense is here recorded for the first time for the Rio Tocantins basin. The occurrence of this species, as well as of the characin Astyanax novae in both the Rio Sapão and Rio Novo/do Sono basins, are here considered to be the only unequivocal examples of fish species that naturally transposed the water divide between the Rio São Francisco and the Rio Tocantins basins effected by the common headwater between Rio Sapão and Rio Galheiros.
\end{abstract}

Keywords: biogeography, common headwater, ichthyofauna, Rio São Francisco basin, Rio Tocantins basin.

LIMA, F.C.T. \& CAIRES, R.A. Peixes da Estação Ecológica Serra Geral do Tocantins, bacias dos Rios Tocantins e São Francisco, com observações sobre as implicações biogeográficas das "águas emendadas" dos Rios Sapão e Galheiros. Biota Neotrop. 11(1): http://www.biotaneotropica.org.br/v11n1/pt/ abstract?article+bn03411012011.

Resumo: Um levantamento preliminar da ictiofauna que ocorre na Estação Ecológica Serra Geral de Tocantins, situada no Sudeste do Estado do Tocantins e Noroeste do Estado da Bahia, é apresentado. A Estação Ecológica Serra Geral de Tocantins situa-se no divisor de águas entre as bacias do Rio São Francisco (Rio Sapão) e Rio Tocantins (bacias dos Rios Novo, Balsas e Manuel Alves). A cabeceira comum ou "água emendada” do Rio Sapão e Rio Galheiros, este um afluente do Rio Novo, situa-se no interior da estação e é considerada na literatura como uma possível área de intercâmbio ictiofaunístico entre a bacia do Rio São Francisco e a bacia do Rio Tocantins. Trinta e cinco espécies de peixes foram registradas dentro da Estação Ecológica Serra Geral de Tocantins e em seu entorno imediato, algumas delas desconhecidas da ciência e possivelmente endêmicas da região. Um total de 111 espécies de peixes foi registrado regionalmente (incluindo espécies de peixes registrados nos trechos do Rio Sapão e do Rio Novo/do Sono abaixo da estação). O acará Cichlasoma sanctifranciscense é aqui registrado pela primeira vez na bacia do Rio Tocantins. A ocorrência desta espécie, bem como do lambari Astyanax novae, no Rio Sapão e no Rio Novo/do Sono, são considerados os únicos exemplos inequívocos de transposição natural de espécies de peixes entre as bacias do Rio São Francisco e Tocantins efetuado pelas águas emendadas dos rios Sapão e Galheiros.

Palavras-chave: biogeografia, águas emendadas, ictiofauna, Rio São Francisco, Rio Tocantins. 


\section{Introdução}

A Estação Ecológica Serra Geral do Tocantins (E.E. Serra Geral do Tocantins) (Figura 1) situa-se na porção sudoeste do Estado do Tocantins e noroeste da Bahia, abarcando porções das cabeceiras de tributários do Rio Tocantins (rios Manoel Alves, Novo e Balsas) e um tributário do Rio São Francisco, o Rio Sapão. A E.E. Serra Geral do Tocantins situa-se, portanto, no divisor de águas entre esses dois sistemas. O divisor nessa região é estabelecido pela Serra Geral do Tocantins, que é a borda ocidental de um patamar planáltico, já em grande parte erodido na bacia do Rio Tocantins, embora alguns pequenos fragmentos, que surgem como morros ou pequenas chapadas, subsistam na área. A bacia do Rio São Francisco drena a porção ainda contínua desse patamar planáltico e que, portanto, vem sendo paulatinamente capturada para a bacia do Rio Tocantins, à medida que a erosão progride em suas bordas. De fato, a existência da cabeceira comum dos rios Sapão (bacia do Rio São Francisco) e Galheiros/Novo (bacia do Rio Tocantins) atesta o efeito da progressão da erosão remontante na captura de antigos tributários da bacia do Rio São Francisco para a bacia do Rio Tocantins. Esse é um fato de grande interesse biogeográfico, como relatado adiante.

A bacia do Rio Tocantins abrange aproximadamente 750.000 $\mathrm{km}$ (Goulding et al. 2003). Historicamente, o Rio Tocantins tem sido tratado como um sistema independente da bacia amazônica, baseado no fato de que há pouca mistura entre as águas do Rio Amazonas e as do Rio Tocantins no estuário de Marajó, aparentemente devido ao "represamento" das águas do Amazonas pelas do Tocantins na região do estreito de Breves (Barthem \& Schwassmann, 1994). Contudo, como notado por Goulding et al. (2003), o Rio Tocantins é um Rio essencialmente amazônico em termos da composição de sua biota, mesmo que ele não possa ser considerado, rigorosamente falando, um tributário do Rio Amazonas. Graças a intensos levantamentos ictiofaunísticos em alguns trechos da bacia realizados nos últimos 30 anos, infelizmente ligados à construção de hidrelétricas, como Tucuruí, Lageado e Serra da Mesa (para Tucuruí, ver Santos et al. 1984, 2004), a fauna de peixes da bacia do Rio Tocantins pode ser considerada hoje relativamente bem conhecida quando comparada à ictiofauna dos outros subsistemas amazônicos. Segundo uma compilação realizada pelos autores, através da consulta de literatura e espécimes de museu, um mínimo de 520 espécies de peixes ocorrem na bacia do Rio Tocantins, $30 \%$ das quais endêmicas a esse sistema. Biogeograficamente, a ictiofauna do Rio Tocantins é claramente mais proximamente relacionada àquela da bacia amazônica, mas essa associação biogeográfica deve ter sido causada por dois processos históricos distintos. Um desses processos é a relativa conectividade existente entre as terras baixas do baixo Amazonas com a depressão tectonicamente ativa do Rio Araguaia, o que propiciou a entrada de muitas espécies originárias da biota da Amazônia Central na bacia do Rio Tocantins, notadamente no Rio Araguaia (Lima \& Ribeiro, 2011). Também existe a relação entre as ictiofaunas dos rios do sul do cráton amazônico, particularmente no presente caso entre as bacias dos rios Tocantins e Xingu. Essas bacias compartilham um extenso divisor de águas, em que intercâmbios faunísticos resultantes da captura de pequenos sistemas hidrográficos devem ter ocorrido continuamente nessa área do escudo brasileiro, que é relativamente suscetível à atividade neotectônica, ou seja, ocorrida do Plioceno (3 m.a.) ao período recente (Lima \& Ribeiro 2011).

A bacia do Rio São Francisco abarca aproximadamente $631.133 \mathrm{~km}$ (Sato \& Godinho, 1999). Sua ictiofauna é uma das mais bem conhecidas da América do Sul (Britski et al. 1984, Sato \& Godinho 1999, Alves \& Pompeu 2001), tendo sido uma das primeiras a receber um estudo monográfico detalhado (Lütken 1875, republicado, em tradução para o português em 2001). Uma compilação realizada pelos autores indicou a existência de no mínimo 180 espécies de peixes nativas ocorrendo nessa bacia (não incluindo nesse cômputo espécies estuarinas que ocasionalmente penetram em água doce), das quais aproximadamente 59\% são endêmicas a esse sistema. Biogeograficamente, a ictiofauna do Rio São Francisco é, como apontado inicialmente por Vari (1988), claramente híbrida em sua origem, apresentado relações com todos os sistemas hidrográficos em seu entorno. Assim, alguns táxons ocorrentes na bacia apresentam relações mais estreitas com a porção superior da bacia do Rio Paraná, o que é evidenciado pela ocorrência de espécies comuns a ambos os sistemas, como Piabina argentea (Characidae, Ribeiro 2006), Cetopsis gobioides (Cetopsidae; Vari et al. 2005), Salminus hilarii (Characidae, Lima 2006) e Corydoras difluviatilis (Britto \& Castro 2002). Relações com rios do leste brasileiro são apontadas também pela ocorrência de grupos monofiléticos comuns a esses sistemas, como os gêneros Pareiorhaphis (Loricariidae, Pereira \& Reis 2002), Neoplecostomus (Loricariidae: Langeani 1990), e as espécies Oligosarcus argenteus (Characidae; Menezes 1987, 1988) e Steindachnerina elegans (Curimatidae: Vari 1988). Por outro lado, alguns táxons pertencendo a grupos monofiléticos de ampla distribuição em drenagens do norte da América do Sul cis-andina, como Pygocentrus piraya (Serrasalmidae, Fink 1993, Hubert et al. 2006) e Curimatella lepidura (Curimatidae: Vari 1988), ocorrem na bacia do Rio São Francisco. Uma relação biogeográfica do Rio São Francisco com a bacia do alto Rio Tocantins é apontada pela existência de grupos monofiléticos ocorrentes em ambas as áreas nos gêneros Cynolebias e Simpsonichthys (Rivulidae: Costa 2001, 2003). Por fim, a bacia do Rio São Francisco é caracterizada pela ocorrência de elementos relictuais, como Franciscodoras marmoratus (Doradidae) e Conorhynchus conirostris (atualmente considerada incertae sedis em Siluriformes) (e.g., De Pinna 1998).

Portanto, o fato da região do Jalapão situar-se no divisor de águas entre as bacias dos rios Tocantins e São Francisco, dois sistemas hidrográficos muito distintos ictiofaunisticamente, a torna de particular interesse biogeográfico. Contudo, faltam estudos detalhados sobre a ictiofauna local. O conhecimento ictiológico na região iniciou-se quando o ictiólogo norte-americano John D. Haseman, no decurso de uma de suas expedições na América do Sul, ascendeu o Rio Sapão, a partir do Rio São Francisco, e, atravessando o divisor de águas, alcançou o Rio Novo, na região da Cachoeira da Velha, na bacia do Rio Tocantins, entre janeiro e fevereiro de 1908 (Haseman \& Eigenmann 1911). Nessa expedição, Haseman chegou à cabeceira comum dos rios Sapão e Galheiros, que ele descreveu como sendo

"...the basin of an old drained mountain lake having a good connection with the Rio Sapon (sic) and Nova (sic), thus uniting the São Francisco and the Amazon basins..." (Haseman \& Eigenmann 1911: 288).

Esses autores concluem notando que essa descoberta representa

"...the confirmation of the rumor that there is a connection between the Rio Tocantins and the Rio São Francisco" (Haseman \& Eigenmann, 1911: 288).

Embora relativamente bem conhecida, o potencial significado biogeográfico dessa "conexão" entre esses dois grandes sistemas hidrográficos nunca foi devidamente estudado pelos ictiólogos. Somente Menezes (1976) utilizou essa evidência de conectividade entre esses dois sistemas hidrográficos, ao apontar que a ocorrência de Galeocharax gulo (Characidae) tanto na bacia amazônica (incluindo Rio Tocantins) como na do São Francisco seria explicável pela

“...direct communication between the Rio Sapão, a tributary of the São Francisco, and the Rio do Sono, a tributary of the Tocantins...” (Menezes, 1976: 45).

Entretanto, esse mesmo autor considerou subsequentemente que o registro de Galeocharax gulo na bacia do Rio São Francisco seria, na verdade, equivocado (Menezes 2007). É preciso notar que 
a cabeceira comum entre os rios Sapão e Galheiros não pode ser de forma alguma comparada à famosa conexão existente entre os rios Negro e Orinoco, o Rio Casiquiare, que é um grande efluente do Rio Orinoco que desemboca no Rio Negro, e que efetivamente conecta os trechos superiores desses dois grandes sistemas hidrográficos (Winemiller et al. 2008), sendo apenas uma área de cabeceira comum.

Portanto, mais que um simples inventário ictiofaunístico, a expedição ictiológica à E.E. Serra Geral de Tocantins constituiu-se em uma oportunidade de entender melhor o potencial papel biogeográfico dessa "água emendada" entre as bacias dos rios Tocantins e São Francisco. Para tanto, as observações realizadas nas nascentes do Sapão, conjugadas à lista das espécies de peixes coletadas em vários trechos da bacia do Rio do Sono e do Rio Sapão, coletados tanto durante a expedição de fevereiro de 2008 como em expedições anteriores à mesma região realizadas por outros ictiólogos, permitiu compreender o real significado desse contato entre esses dois grandes sistemas hidrográficos.

\section{Material e métodos}

Dezessete pontos (7 dos quais situados dentro dos limites da E.E. Serra Geral de Tocantins - EESGT; Apêndice 1) foram amostrados ictiologicamente entre o final de janeiro e o início de fevereiro de 2008, compreendendo as bacias dos rios Manuel Alves e Sono (bacia do Rio Tocantins), e do Rio Sapão (bacia do Rio São Francisco). Coletas foram realizadas basicamente com redes de arrasto $(2 \times$ 1 metros, malha $1 \mathrm{~mm}$ e $6 \times 1 \mathrm{~m}$, malha $3 \mathrm{~mm}$ ) e puçás retangulares $(1 \times 0.6 \mathrm{~m}$, malha $1 \mathrm{~mm})$. Em algumas localidades, alguns peixes foram coletados com puçás durante mergulho livre. Devido à época da coleta, realizada em plena estação chuvosa, os rios e riachos do Jalapão encontravam-se cheios, o que dificultou a coleta em alguns pontos e praticamente a inviabilizou em outros (por exemplo, na cabeceira do Rio Sapão e no Rio Peixinho). O material foi fixado em formol $10 \%$, e ao chegar ao laboratório, transferido para álcool $70^{\circ}$. Todos os espécimes foram catalogados na coleção do Museu de Zoologia da Universidade de São Paulo (MZUSP; números de catálogo 98461 a 98539). Também foi examinado o material depositado no MZUSP coletado pelos ictiólogos Osvaldo Oyakawa, Alberto Akama, Cristiano Moreira, José C. Nolasco e Valdener Garutti em quatro expedições distintas, ao Rio Sapão (1998), Rio Novo (2001) e rios Manuel Alves e Sapão (agosto e novembro de 2002). A lista publicada por Aloísio et al. (2005) de peixes da bacia do Rio Novo/do Sono foi analisada, e o material coletado por esses autores depositado no MZUSP revisado, para confirmar as identificações das espécies e retificar eventuais identificações incorretas.

\section{Resultados}

Na região de estudo, compreendendo os limites das EESGT e seu entorno imediato, dentro do alto curso das bacias dos rios Manoel Alves, Novo, Sapão e Balsas, foram registradas 35 espécies (Tabela 1). Destas, 26 espécies foram coletadas dentro dos limites da unidade de conservação, enquanto que nove espécies obtidas apenas em sítios de amostragem no entorno imediato da unidade. Tais espécies, amostradas em sítios muito próximos e em drenagens diretamente conectadas com a EESGT, muito provavelmente também ocorrem dentro da área protegida, e portanto estão incluídas na listagem da Unidade (Tabela 1). Numa escala mais ampla, em toda a região do Jalapão (incluindo todo o entorno da EESGT e do contíguo P.E. do Jalapão) foram registradas aproximadamente 111 espécies de peixes (Tabela 6 ).

Não existiam levantamentos prévios publicados da região da EESGT e seu entorno imediato. Registros de algumas poucas espécies foram publicados do Rio Sapão e do Rio do
Sono, baseado no material coletado por John Haseman em 1908. Foram registrados Bryconamericus novae Eigenmann \& Henn, Moenkhausia sanctaefilomenae (Steindachner) e Cichlasoma araguaiense Kullander na Cachoeira da Velha, no Rio Novo, Moenkhausia sanctaefilomenae e Cichlasoma sanctifranciscense no Rio Sapão na localidade de "Prazeres", e Astyanax novae em ambas as localidades (Eigenmann 1917, p. 10, 1921, p. 259, 1927, p. 368, Haseman 1911, p. 339, Kullander 1983, p. 240). Dentre estas espécies, Astyanax novae e Bryconamericus novae têm como localidade-tipo o Rio Sapão em "Prazeres" (nome pelo qual a região da cabeceira do Rio Sapão é até hoje conhecida; C. Nogueira, com. pess.) e o Rio Novo na Cachoeira da Velha, respectivamente. Bryconamericus novae não foi coletada recentemente na localidade-tipo, embora duas espécies de Knodus (um gênero relacionado a Bryconamericus que é por alguns, considerado como um sinônimo deste) tenham sido coletadas no Rio Novo, na região da Cachoeira da Velha. Nenhuma das duas, entretanto, concorda com a descrição de Bryconamericus novae. Coleta de material topotípico e uma revisão do grupo são necessárias para um estabelecimento mais adequado da identidade desta espécie.

Quanto à família Cichlidae, Haseman (1911, p. 339) registrou Cichlasoma bimaculatum no Rio do Sono e no Rio Sapão em Prazeres. Kullander (1983, p. 240), em sua revisão do gênero Cichlasoma, considerou o registro do Rio do Sono como sendo Cichlasoma araguaiense, e o registro do Rio Sapão como pertencendo a Cichlasoma sanctifranciscense. Essas identificações foram feitas, contudo, sem o exame dos espécimes estudados por Haseman (1911), ficando implícito que foram baseadas na suposição de que Cichlasoma araguaiense seria a única espécie do gênero a ocorrer na bacia do Rio Tocantins, enquanto que no Rio São Francisco ocorreria apenas Cichlasoma sanctifranciscense. O exame de espécimes recentemente coletados na bacia do Rio do Sono/Novo, comparados àqueles do Rio Sapão (Apêndice 2), mostrou que a Cichlasoma a ocorrer na bacia do Rio do Sono/ Novo é, na realidade, Cichlasoma sanctifranciscense. Esses exemplares apresentam manchas escuras grandes na cabeça e uma contagem de quatro raios duros na nadadeira anal, características típicas de Cichlasoma sanctifranciscense (Figura 2), ao passo que $C$. araguaiense é uma espécie com manchas corporais menos marcadas, sem grandes manchas na cabeça, e tipicamente com apenas três espinhos na nadadeira anal (Kullander 1983). Interessantemente, baseado no exame de material do MZUSP, Cichlasoma araguaiense parece ser a espécie do gênero a ocorrer na bacia do alto Rio Tocantins no Estado de Goiás e também na bacia do Rio Manuel Alves da Natividade, Estado de Tocantins (Apêndice 2). Isso sugere fortemente que a população de Cichlasoma sanctifranciscense que ocorre na bacia do Rio do Sono teria invadido esse sistema hidrográfico através da cabeceira comum entre o Rio Sapão e o Rio Galheiros, enquanto que o resto da bacia do Rio Tocantins, incluindo a bacia do Rio Manuel Alves da Natividade, é habitado pela espécie que é bem distribuída nessa bacia, Cichlasoma araguaiense.

É preciso notar que a presente listagem de peixes da E.E. Serra Geral do Tocantins é extremamente preliminar, e que muitas coletas adicionais serão ainda necessárias para tornar a ictiofauna dessa unidade de conservação relativamente bem conhecida. Como mencionado no item "Material e métodos", a expedição foi realizada durante o período chuvoso, e o elevado volume de águas dificultou ou virtualmente inviabilizou a coleta em diversos dos pontos. De qualquer forma, por se tratar de uma região alta, os rios que drenam a E.E. Serra Geral do Tocantins apresentam as características esperadas para cursos d'água em região de cabeceiras, i.e., forte correnteza, profundidade relativamente elevada e águas transparentes, o que torna a coleta de peixes muito mais difícil que a realizada em cursos d'água em áreas mais baixas. A isso se soma o fato da dificuldade de 
acesso aos rios e ribeirões dentro dos limites da E.E. Serra Geral do Tocantins, uma área protegida relativamente extensa e com poucas e precárias estradas cortando a estação ecológica, o que resultou em poucos pontos amostrais situados de fato dentro dos limites da unidade de conservação. Em particular, áreas extensas das bacias do Rio Balsas e do alto Rio Novo situadas dentro dos limites da E.E. Serra Geral do Tocantins (Figura 1) são relativamente pouco acessíveis, e não foram amostradas de modo adequado no presente estudo. A dificuldade de acesso é refletida também pelo fato de que, aparentemente, anteriormente à expedição de fevereiro de 2008, não existiam coleções ictiológicas efetuadas dentro dos limites da E.E. Serra Geral do Tocantins, exceção feita à coleta de Haseman (1911, p. 339) no Rio Sapão em Prazeres.

Tendo em vista o pouco conhecimento da diversidade de peixes no interior da E.E. Serra Geral do Tocantins, são aqui incluídas e discutidas listas das espécies de peixes coletadas na bacia do Rio Manuel Alves da Natividade nas imediações do município de Rio da Conceição, na bacia do Rio Novo/Rio do Sono, do trecho situado fora da E.E. Serra Geral do Tocantins até a Cachoeira da Velha, e do Rio Sapão. Obviamente, não é possível assegurar que as espécies registradas nas adjacências da E.E. Serra Geral do Tocantins ocorram dentro da unidade de conservação. A E.E Serra Geral do Tocantins situa-se numa região alta, onde nascem tributários dos rios acima citados, além de tributários do Rio das Balsas, um afluente do Rio Tocantins. Regiões de cabeceiras são caracterizadas por possuírem comunidades ictiofaunísticas mais pobres que os trechos de jusante, um resultado tanto da dificuldade de colonização devido à presença de barreiras (corredeiras/cachoeiras), quanto por fatores ecológicos (menor volume de águas, baixa diversidade de habitats, oligotrofismo). A seguir, a ictiofauna encontrada em cada uma desses subsistemas é analisada separadamente, levando-se em conta os diferentes fatores atuantes na ocorrência e na distribuição da fauna de cada região considerada.

\section{Bacia do Rio Manuel Alves da Natividade}

O Rio Manuel Alves da Natividade (não confundir com o homônimo Rio Manuel Alves, situado na região centro-norte do Estado do Tocantins) é um tributário do Rio Tocantins, que tem suas cabeceiras na porção sul e sudoeste da E.E. Serra Geral do

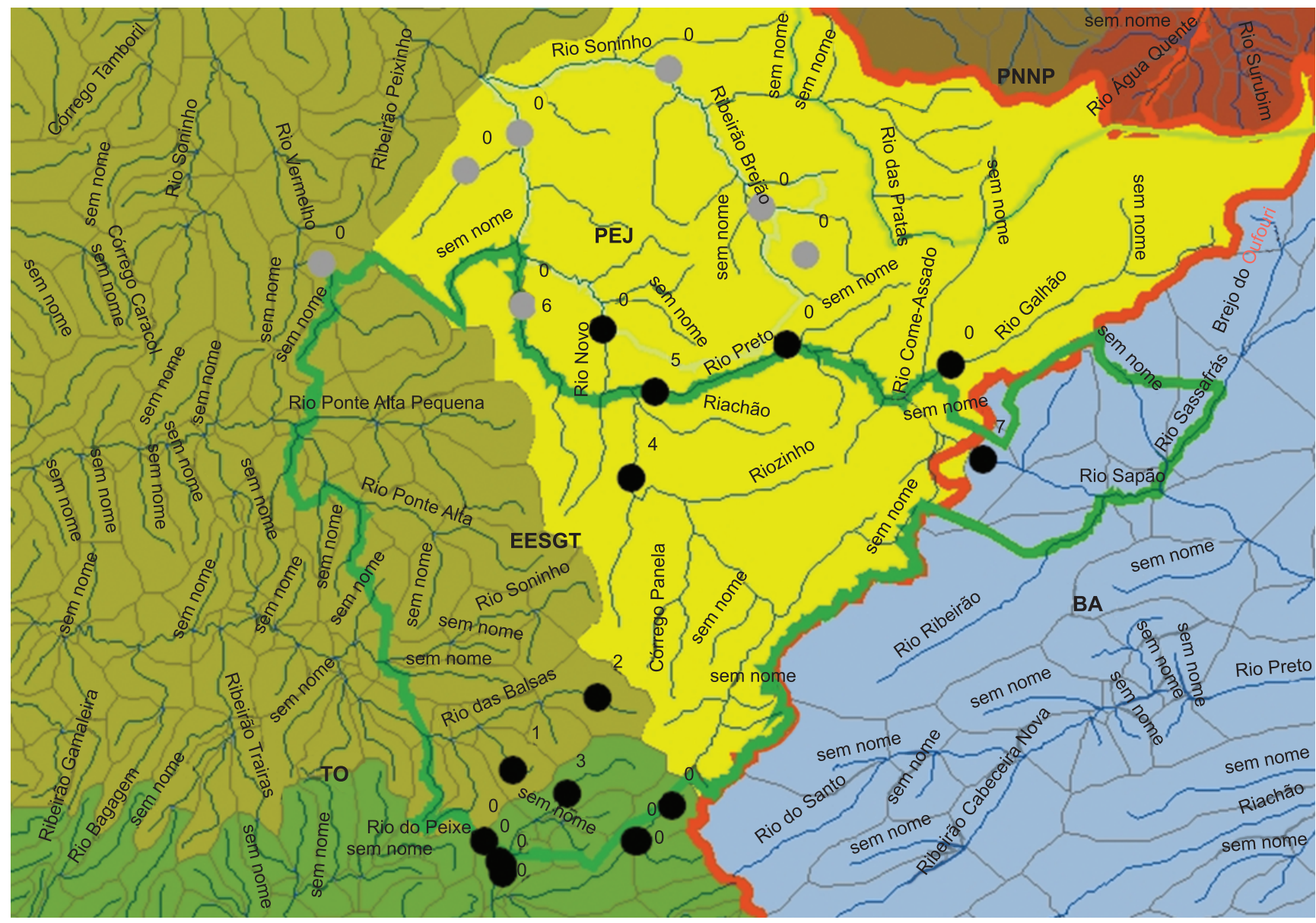

Figura 1. Mapa da região da Estação Ecológica Serra Geral de Tocantins, mostrando os limites da estação (em verde) e os pontos de coleta de peixes realizados no interior da estação e em seu entorno amostrados pela expedição de fevereiro de 2008 e por expedições prévias, cujo material foi analisado (bolas cinzas e pretas). Localidades da expedição de fevereiro de 2008 no interior da E.E. Serra Geral do Tocantins numerados de 1 a 7 , de acordo com a lista de localidades constante no Apêndice 1. Verde-claro: bacia do rio Novo/do Sono. Verde-musgo: Bacia do rio Balsas. Verde-escuro: Bacia do rio Manuel Alves da Natividade. Azul: Bacia dos rios Sapão/Preto. castanho: Bacia do rio Parnaíba.

Figure 1. Map from the Serra Geral de Tocantins ecological station and surroundings, showing the borderlines of the station (indicated in green) and collecting sites within the station and surrounding area sampled during the expedition of February 2008 and previous expeditions (gray and black dots). Collecting sites of the expedition of February 2008 within the Serra Geral do Tocantins ecological station numbered 1-7 (collecting sites described in the Appendix 1). Light green: Rio Novo/rio do Sono basin. Moss green: Rio Balsas basin. Dark green: Rio Manuel Alves da Natividade basin. Blue: Rio Sapão/rio Preto basin. Chestnut: Rio Parnaíba basin. 
Tabela 1. Espécies de peixes registradas na E.E. Serra Geral do Tocantins. 1 - Bacia do Rio Manuel Alves da Natividade. 2 - Bacia do Rio das Balsas. 3 - Bacia do Rio Novo. 4 - Bacia do Rio Sapão. (X): espécie coletada no entorno da E.E. Serra Geral do Tocantins, muito provavelmente ocorrendo no interior da mesma. Table 1. Fish species recorded at Serra Geral do Tocantins Ecological Station. 1 - Rio Manuel Alves da Natividade basin. 2 - Rio das Balsas basin. 3 - Rio Novo basin. 4 - Rio Sapão basin; (X): species collected near Serra Geral do Tocantins Ecological Station, with very likely occurrence within the ecological station.

\begin{tabular}{|c|c|c|c|c|}
\hline Espécies & 1 & 2 & 3 & 4 \\
\hline \multicolumn{5}{|l|}{ Characiformes } \\
\hline \multicolumn{5}{|l|}{ Anostomidae (1) } \\
\hline Leporinus sp. & - & - & $X$ & - \\
\hline \multicolumn{5}{|l|}{ Crenuchidae (4) } \\
\hline Characidium cf. zebra Eigenmann, 1909 & - & - & $\mathrm{X}$ & - \\
\hline Characidium sp. 1 "1.1. interrompida" & $\mathrm{X}$ & - & - & - \\
\hline Characidium sp. 2 "jobertina" & - & - & $\mathrm{X}$ & - \\
\hline Characidium sp. 3 "jobertina X xanthopterum" & - & - & $(\mathrm{X})$ & - \\
\hline \multicolumn{5}{|l|}{ Erythrinidae (2) } \\
\hline Hoplerythrinus unitaeniatus (Agassiz, 1829) & - & $\mathrm{X}$ & - & $\mathrm{X}$ \\
\hline Hoplias cf. malabaricus (Bloch, 1794) & - & - & $(\mathrm{X})$ & - \\
\hline \multicolumn{5}{|l|}{ Characidae (15) } \\
\hline Acestrorhynchus falcatus (Bloch, 1794) & - & - & $\mathrm{X}$ & - \\
\hline Astyanax novae Eigenmann, 1911 & $\mathrm{X}$ & - & $\mathrm{X}$ & - \\
\hline Bryconops sp. 1 "Rio Novo" & - & - & $\mathrm{X}$ & - \\
\hline Bryconops sp. 2 "Rio Preto" & - & - & $\mathrm{X}$ & - \\
\hline Bryconops sp. 3 "Frito Gordo" & - & - & $\mathrm{X}$ & - \\
\hline Caiapobrycon tucurui Malabarba \& Vari, 2000 & $\mathrm{X}$ & - & - & - \\
\hline Creagrutus britskii Vari \& Harold, 2001 & $\mathrm{X}$ & - & - & - \\
\hline Knodus cf. savannensis Géry, 1961 & - & $\mathrm{X}$ & - & - \\
\hline Knodus sp. 1 "Rio Novo" & - & - & $\mathrm{X}$ & - \\
\hline Hasemania sp. & - & - & $\mathrm{X}$ & - \\
\hline Hemigrammus sp. 1 "gorducho" & $\mathrm{X}$ & - & - & - \\
\hline Hemigrammus sp. 2 "Sapão” & - & - & - & $\mathrm{X}$ \\
\hline Hyphessobrycon sp. 1 "vermelhinho" & - & - & $(\mathrm{X})$ & - \\
\hline Hyphessobrycon sp. 2 "garganta vermelha" & - & - & $(\mathrm{X})$ & - \\
\hline Hyphessobrycon sp. 3 "falsa Moenkhausia lepidura" & - & - & $(\mathrm{X})$ & - \\
\hline \multicolumn{5}{|l|}{ Siluriformes } \\
\hline \multicolumn{5}{|l|}{ Auchenipteridae (2) } \\
\hline Centromochlus sp. & - & $\mathrm{X}$ & - & - \\
\hline Parauchenipterus cf. galeatus & - & - & $(\mathrm{X})$ & - \\
\hline \multicolumn{5}{|l|}{ Heptapteridae (3) } \\
\hline Rhamdia cf. quelen (Quoy \& Gaimard, 1824) & - & - & $(\mathrm{X})$ & - \\
\hline Phenacorhamdia sp. "longa" & - & $\mathrm{X}$ & - & - \\
\hline Phenacorhamdia sp. "curta" & - & $\mathrm{X}$ & - & - \\
\hline \multicolumn{5}{|l|}{ Gymnotiformes } \\
\hline \multicolumn{5}{|l|}{ Gymnotidae (1) } \\
\hline Gymnotus sp. & - & - & $(\mathrm{X})$ & - \\
\hline \multicolumn{5}{|l|}{ Sternopygidae (2) } \\
\hline Sternopygus macrurus (Bloch \& Schneider, 1801) & - & - & $(\mathrm{X})$ & - \\
\hline Eigenmannia sp. & $\mathrm{X}$ & - & $(\mathrm{X})$ & - \\
\hline \multicolumn{5}{|l|}{ Cyprinodontiformes } \\
\hline \multicolumn{5}{|l|}{ Rivulidae (3) } \\
\hline Rivulus cf. decoratus Costa, 1989 & - & - & - & $\mathrm{X}$ \\
\hline Rivulus zygonectes Myers, 1927 & - & $\mathrm{X}$ & - & - \\
\hline Rivulus sp. "Rio Novo" & - & - & $X$ & - \\
\hline \multicolumn{5}{|l|}{ Perciformes } \\
\hline \multicolumn{5}{|l|}{ Cichlidae (2) } \\
\hline Cichlasoma sanctifranciscense Kullander, 1983 & - & - & $\mathrm{X}$ & - \\
\hline Crenicichla cf. inpai Ploeg, 1991 & - & - & $\mathrm{X}$ & - \\
\hline
\end{tabular}


Tocantins, pouco acima do município de Rio da Conceição. Nesta bacia, foram realizadas coletas no Rio Manuel Alves da Natividade e afluentes nos arredores do município de Rio da Conceição. Material previamente coletado por expedições do MZUSP na região foi também incluído. Dez localidades foram amostradas, das quais uma única (Rio Cascavel) encontra-se dentro dos limites da E.E. Serra Geral do Tocantins. Trinta e uma espécies foram coletadas, das quais apenas cinco espécies foram registradas dentro da E.E. Serra Geral do Tocantins (Tabela 2). É bastante provável que muitas das espécies de peixes registradas na bacia do Rio Manuel Alves da Natividade nas proximidades de Rio da Conceição ocorram dentro da E.E. Serra Geral do Tocantins, uma vez que o Rio Cascavel, o único ponto amostrado da bacia situado nos limites da unidade de conservação, é um trecho de cabeceiras do Rio Peixinho, não tendo sido possível acessar as porções mais baixas desse Rio situadas dentro da Estação Ecológica.

\section{Bacia do Rio das Balsas}

O Rio das Balsas é um afluente do Rio do Sono, mas preferimos considera-lo aqui como uma unidade hidrográfica distinta devido à sua grande extensão. A Tabela 3 inclui apenas as espécies coletadas em dois riachos de cabeceira pertencentes à bacia do Rio das Balsas, ambos situados dentro da E.E. Serra Geral do Tocantins, uma vez que aparentemente, pouco ou nenhum material do trecho inferior da bacia do Rio das Balsas existe em coleções ictiológicas. Considerando o baixíssimo número de pontos amostrados (2) e de espécies coletadas (6) (Tabela 3), fica claro que muita coleta terá de ser ainda realizada nesse subsistema até que ele possa ser considerado como satisfatoriamente conhecido ictiologicamente.

\section{Bacia do Rio Novo/do Sono}

A bacia do Rio Novo, nome local do trecho superior do Rio do Sono, um importante afluente do Rio Tocantins, compreende os maiores cursos d'água a atravessarem a E.E. Serra Geral do Tocantins. Além do próprio Rio Novo, afluentes de porte relativamente grande, como o Rio Preto e o Rio Verde, também estão dentro dos limites da estação ecológica. Não surpreendentemente, essa bacia é a que, até o momento, abarca a maior diversidade ictiofaunística na região do Jalapão, com um total de 65 espécies registradas, das quais 13 com ocorrência registrada, e outras 10 com ocorrência quase certa, dentro da E.E. Serra Geral do Tocantins (Tabela 4). Em parte, essa

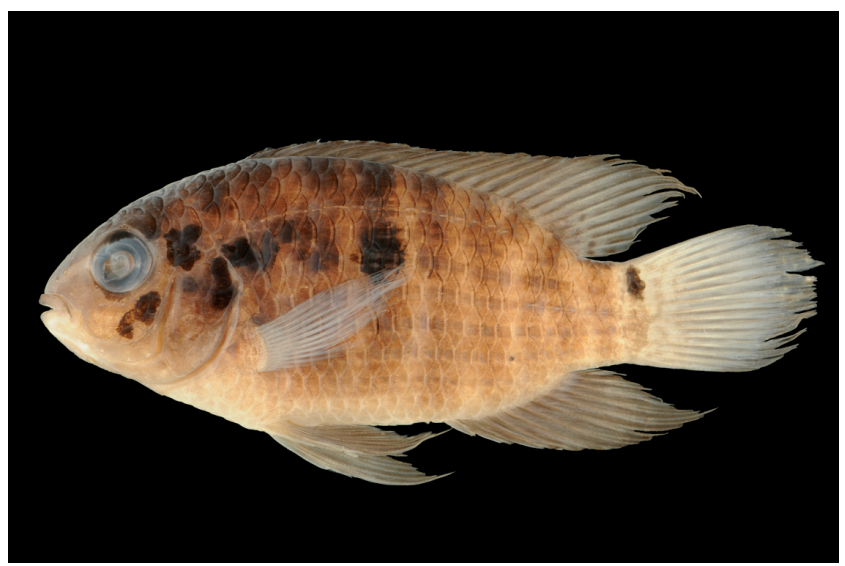

Figura 2. Cichlasoma sanctifranciscense, MZUSP 98498, 61,5 mm CP: Mateiros, Rio Novo, perto da foz do córrego Lajeiro, E.E. Serra Geral do Tocantins.

Figure 2. Cichlasoma sanctifranciscense, MZUSP 98498, $61.5 \mathrm{~mm}$ SL: Mateiros, Rio Novo, near mouth of córrego Lajeiro, Serra Geral do Tocantins ecological station. maior diversidade se deve ao fato de que esse é o sub-sistema do Rio Tocantins a drenar a região da E.E. Serra Geral do Tocantins que foi mais amostrado durante a expedição, e que contava com várias localidades previamente inventariadas (Figura 1). As espécies aqui consideradas como quase certamente ocorrendo dentro da E.E. Serra Geral do Tocantins são aquelas que foram coletadas nas proximidades da estação ecológica, i.e., no Rio Novo pouco abaixo do trecho que cruza a unidade de conservação, ou em afluentes do Rio Preto (especificamente, Rio Galheiros e ribeirão Brejão) pouco acima da estação ecológica. Por outro lado, a maioria das 32 espécies de peixes registradas nessa bacia (mas que não foram encontradas nas proximidades da E.E. Serra Geral do Tocantins) foi coletada no Rio do Sono na região da Cachoeira da Velha. Segundo moradores locais, a porção superior do Rio Novo é naturalmente depauperada em espécies de peixes. Supostamente, a Cachoeira da Velha deve constituir uma barreira à dispersão de muitas espécies de peixes amplamente distribuídas na bacia do Rio Tocantins e na bacia amazônica de uma forma geral e que foram detectadas abaixo dela, como, por exemplo, a raia (Potamotrygon hystrix), a bicuda (Boulengerella cuvieri), a cachorra (Hydrolycus tatauaia), a matrinchã (Brycon sp.), o pacu-prata (Myloplus cf. torquatus), o dourado (Salminus sp.) e o peixe-elétrico (Electrophorus electricus). Como a Cachoeira da Velha situa-se a uma considerável distância do limite norte da estação ecológica (ca. 20 km) e é ainda mais longe do trecho do Rio Novo em que ele deixa de correr inteiramente dentro da mesma (46 km em linha reta), parece bastante seguro afirmar-se que uma considerável parte da diversidade de peixes a ocorrer na bacia do Rio do Sono não ocorre dentro dos limites da E.E. Serra Geral do Tocantins.

\section{Bacia do Rio Sapão}

Esse afluente do Rio Preto, por sua vez afluente do Rio Grande, que é o maior tributário do Rio São Francisco no Estado da Bahia, tem certa notoriedade por ter uma cabeceira compartilhada com o Rio Galheiros, este sendo um afluente do Rio Novo, na bacia do Rio Tocantins. A cabeceira comum a esses dois rios (conhecida como "Lagoa dos três rios") encontra-se dentro dos limites da E.E. Serra Geral do Tocantins e foi visitada durante a expedição de fevereiro de 2008. Infelizmente, o grande volume de águas durante o período da visita praticamente impossibilitou a realização de coletas nessa localidade. A lista abaixo é baseada em material coletado em três expedições distintas, realizadas entre 1998 e 2002 por ictiólogos do MZUSP, no trecho médio e inferior da bacia do Rio Sapão. Um total de 35 espécies de peixes foi encontrado no Rio Sapão, das quais apenas duas foram coletadas na cabeceira do Rio Sapão, uma terceira (Hoplerythrinus unitaeniatus) tendo sido observada nessa localidade e assim também incluída (Tabela 5). São incluídas as duas espécies de peixes coletadas por Haseman no Rio Sapão em Prazeres, que é o nome da região em que a cabeceira comum do Sapão e Galheiros se situa. Não é possível prever quantas espécies conhecidas do trecho médio e inferior do Rio Sapão eventualmente ocorreriam dentro da E.E. Serra Geral do Tocantins, e coletas adicionais são necessárias para que uma lista adequada da diversidade ictiofaunística nesse trecho do Rio seja conhecida.

\section{Discussão}

O número de espécies de peixes registrados em rios da bacia do Rio Tocantins na E.E. Serra Geral do Tocantins (35) é baixo, considerando que esse sistema hidrográfico detém uma alta riqueza ictiofaunística (> $520 \mathrm{spp}$.). Como notado acima, esse baixo número de espécies é, em parte, resultado de problemas amostrais, i.e., um baixo número de pontos amostrados devido às dificuldades de acesso 
Tabela 2. Peixes da bacia do Rio Manuel Alves da Natividade, no interior da E.E. Serra Geral do Tocantins e entorno. Lotes-testemunho estão catalogados na coleção do MZUSP.

Table 2. Fishes from Rio Manuel Alves da Natividade basin, at the E.E. Serra Geral do Tocantins and surrounding areas. Voucher lots are all cataloged at MZUSP.

\section{E.E. Serra Geral do Entorno Lote-testemunho}

Tocantins

Characiformes

Anostomidae (2)

Leporinus bistriatus Britski, 1997

$\begin{array}{lll}- & X & 83858 \\ - & X & 83860\end{array}$

Crenuchidae (1)

Characidium sp. 1 "1.1. interrompida"

Erythrinidae (3)

Hoplerythrinus unitaeniatus (Agassiz, 1829)

Hoplias aimara (Valenciennes, 1847)

Hoplias cf. malabaricus (Bloch, 1794)

Characidae (11)

Astyanax novae Eigenmann, 1911

Astyanax sp. 1 (grupo. scabripinnis)

Astyanax sp.

Bryconops sp.

Caiapobrycon tucurui Malabarba \& Vari, 2000

Creagrutus britskii Vari \& Harold, 2001

Creagrutus saxatilis Vari \& Harold, 2001

Knodus cf. savannensis Géry, 1961

Hemigrammus sp. 1 "gorducho"

Moenkhausia sp.

Roeboexodon guyanensis (Puyo, 1948)

Tetragonopterus $\mathrm{sp}$.

Siluriformes

Trichomycteridae (2)

Ituglanis sp.

Homodiaetus sp.

Callichthyidae (1)

Aspidoras sp.

Loricariidae (3)

Harttia punctata Rapp Py-Daniel \& Oliveira, 2001

Loricaria sp.

Hypostomus sp.

Auchenipteridae (1)

Tatia sp.

Heptapteridae (2)

Cetopsorhamdia sp.

Phenacorhamdia sp. "curta"

Gymnotiformes

Sternopygidae (1)

Eigenmannia sp.

Cyprinodontiformes

Rivulidae (1)

Rivulus zygonectes Myers, 1927

Perciformes

Cichlidae (3)

Cichlasoma araguaiense Kullander, 1983

Geophagus cf. altifrons Heckel, 1840

Retroculus lapidifer (Castelnau, 1855)
X

$\mathrm{X}$

$\begin{array}{ll}- & X\end{array}$

$-\quad X$

- $\quad \mathrm{X}$

$-\quad x$

$-\quad \mathrm{X}$

$-\quad X$

- $\quad X$

X -

$\mathrm{X} \quad \mathrm{X}$

- $\quad X$

- $\quad X$

$\mathrm{X}$

$-$

$-$

$-$

$-$

$-$

$-$

$-\quad X$

- $\quad$ X

- $\quad \mathrm{X}$

- $\quad X$

- $\quad X$

- $\quad \mathrm{X}$

$-\quad X$

- $\quad \mathrm{X}$

X

X

98469,98471

- $\quad$ X

98470,98487

98472, 98477, 98481

84061, 98461

83877

83873

83869

84098

98476

84055

98473

$84062,98474,98479,98482$

84053

84181, 98480, 98483

$98475,98484,98485,98486,98489$

84052

83868

83866

83871

84050

98488

83864

84056

85790

82348

87237, 92613

87237,9261
$X \quad 98478$

$-\quad \mathrm{X}$

84054

83875

82126 
Tabela 3. Peixes da bacia do Rio das Balsas coletados na E.E. Serra Geral do Tocantins. Lotes-testemunho estão catalogados na coleção do MZUSP.

Table 3. Fishes from Rio das Balsas collected at Serra Geral do Tocantins ecological station. Voucher lots are all cataloged at MZUSP.

\begin{tabular}{lc}
\multicolumn{1}{c}{ Espécies } & Lote-testemunho \\
\hline Characiformes & \\
Erythrinidae (1) & 98461 \\
Hoplerythrinus unitaeniatus (Agassiz, 1829) & \\
Characidae (1) & 98465,98462 \\
Knodus cf. savannensis Géry, 1961 & \\
Siluriformes & 98464 \\
Auchenipteridae (1) & 98467 \\
Centromochlus sp. & 98466 \\
Heptapteridae (2) & \\
Phenacorhamdia sp. "longa" & \\
Phenacorhamdia sp. "curta" & \\
Cyprinodontiformes & 98463,98468 \\
Rivulidae (1) & \\
Rivulus zygonectes Myers, 1927 & \\
\hline
\end{tabular}

Tabela 4. Peixes da bacia do Rio Novo/rio do Sono, no interior da E.E. Serra Geral do Tocantins e entorno. * Espécies citadas por Aloísio et al. (2005), não examinadas no presente estudo (material não depositado no MZUSP). 1 - Leporinus sp. de Aloísio et al. (2005). 2 - Mylesinus schomburgkii de Aloísio et al. (2005). 3 -Acestrocephalus sardina de Aloísio et al. (2005). 4 - Moenkhausia sanctaefilomenae de Aloísio et al. (2005). 5-Salminus cf. hilarii de Aloísio et al. (2005). 6 - Geophagus surinamensis de Aloísio et al. (2005). (X): Espécies coletadas em tributários do Rio Novo acima da área da E.E. Serra Geral do Tocantins, e de ocorrência muito provável no interior da mesma. Lotes-testemunho estão catalogados na coleção do MZUSP.

Table 4. Fishes from the Rio Novo/rio do Sono basin, at the E.E. Serra Geral do Tocantins and surrounding areas. * Species recorded by Aloísio et al. (2005), not examined during the present study (specimens not deposited at MZUSP). 1 - Leporinus sp. in Aloísio et al. (2005). 2- Mylesinus schomburgkii in Aloísio et al. (2005). 3 - Moenkhausia sanctaefilomenae in Aloísio et al. (2005). 4- Acestrocephalus sardina in Aloísio et al. (2005). 5- Salminus cf. hilarii in Aloísio et al. (2005). 6 - Geophagus surinamensis in Aloísio et al. (2005). (X): Species collected in tributaries of the Rio Novo above Serra Geral do Tocantins ecological station, which probably occur within the protected area. Voucher lots are all cataloged at MZUSP.

\begin{tabular}{|c|c|c|c|}
\hline Espécies & $\begin{array}{c}\text { E.E. Serra } \\
\text { Geral do } \\
\text { Tocantins }\end{array}$ & Entorno & Lote-testemunho \\
\hline \multicolumn{4}{|l|}{ Chondrichthyes } \\
\hline \multicolumn{4}{|l|}{ Myliobatiformes } \\
\hline \multicolumn{4}{|l|}{ Potamotrygonidae (1) } \\
\hline Potamotrygon cf. histrix* (Müller \& Henle, 1834) & - & $\mathrm{X}$ & - \\
\hline \multicolumn{4}{|l|}{ Characiformes } \\
\hline \multicolumn{4}{|l|}{ Anostomidae (2) } \\
\hline Leporinus ortomaculatus ${ }^{1}$ Garavello, 2000 & - & $\mathrm{X}$ & 83525,83484 \\
\hline Leporinus sp. & $\mathrm{X}$ & - & 98493 \\
\hline \multicolumn{4}{|l|}{ Curimatidae (1) } \\
\hline Cyphocharax cf. spilurus Günther, 1864 & - & $\mathrm{X}$ & $83501,83504,97498$ \\
\hline \multicolumn{4}{|l|}{ Hemiodontidae (2) } \\
\hline Hemiodus ternetzi Myers, 1927 & - & - & 83506,83508 \\
\hline Hemiodus unimaculatus (Bloch, 1794) & - & - & 83518 \\
\hline \multicolumn{4}{|l|}{ Crenuchidae (3) } \\
\hline Characidium cf. zebra Eigenmann, 1909 & $\mathrm{X}$ & $\mathrm{X}$ & $98549,98496,98502,98512,98528,83491$ \\
\hline Characidium sp. 2 "jobertina" & $\mathrm{X}$ & $\mathrm{X}$ & 98503 \\
\hline Characidium sp. 3 “jobertina X xanthopterum” & $(\mathrm{X})$ & $\mathrm{X}$ & 98522 \\
\hline \multicolumn{4}{|l|}{ Ctenoluciidae (1) } \\
\hline Boulengerella cuvieri* (Agassiz, 1829) & - & $\mathrm{X}$ & - \\
\hline \multicolumn{4}{|l|}{ Erythrinidae (2) } \\
\hline Hoplerythrinus unitaeniatus (Agassiz, 1829) & - & $\mathrm{X}$ & 98553,98555 \\
\hline Hoplias cf. malabaricus (Bloch, 1794) & $(\mathrm{X})$ & $\mathrm{X}$ & $98524,83517,98562,98550,98616,98558$ \\
\hline Serrasalmidae (4) & & & \\
\hline
\end{tabular}


Tabela 4. Continuação...

Table 4. Continued...

\begin{tabular}{|c|c|c|c|}
\hline Espécies & $\begin{array}{c}\text { E.E. Serra } \\
\text { Geral do } \\
\text { Tocantins }\end{array}$ & Entorno & Lote-testemunho \\
\hline Acnodon normani Gosline, 1951 & - & $\mathrm{X}$ & 83522 \\
\hline Mylesinus paucisquamatus ${ }^{2}$ Jégu \& Santos, 1988 & - & $\mathrm{X}$ & 83527 \\
\hline Myleus setiger Müller \& Troschel, 1844 & - & $\mathrm{X}$ & 83531,83532 \\
\hline Myloplus cf. torquatus (Kner, 1858) & - & $\mathrm{X}$ & 83530,83529 \\
\hline Characidae (28) & - & $\mathrm{X}$ & \\
\hline Acestrocephalus acutus ${ }^{3}$ Menezes, 2006 & - & $\mathrm{X}$ & 83487,97939 \\
\hline Acestrocephalus stigmatus Menezes, 2006 & - & $\mathrm{X}$ & 97938 \\
\hline Acestrorhynchus falcatus (Bloch, 1794) & - & $\mathrm{X}$ & $83514,97941,98505$ \\
\hline Acestrorhynchus microlepis (Schomburgk, 1841) & - & $\mathrm{X}$ & 83513 \\
\hline Astyanax novae Eigenmann, 1911 & $X$ & $X$ & $\begin{array}{l}83491,83497,98491,98504 \\
98508,98527,98533,98538\end{array}$ \\
\hline Astyanax sp. & - & $\mathrm{X}$ & 83496 \\
\hline Brycon sp.* & - & $\mathrm{X}$ & - \\
\hline Bryconops alburnoides (Kner, 1859) & - & $\mathrm{X}$ & 97944 \\
\hline Bryconops sp. 1 "Rio Novo" & $\mathrm{X}$ & $\mathrm{X}$ & $97945,98560,98492,98529$ \\
\hline Bryconops sp. 2 "Rio Preto" & $\mathrm{X}$ & - & 98500 \\
\hline Bryconops sp. 3 "Frito Gordo" & $\mathrm{X}$ & - & 98513 \\
\hline Creagrutus saxatilis Vari \& Harold, 2001 & & & 97952 \\
\hline Knodus sp. 1 "Rio Novo" & $\mathrm{X}$ & $\mathrm{X}$ & $98526,98517,98499,98603,98497,98535$ \\
\hline Knodus sp. 2 & - & $\mathrm{X}$ & 97935 \\
\hline Hasemania sp. & $\mathrm{X}$ & - & $98494,98507,98510$ \\
\hline Hydrolycus armatus* (Jardine \& Schomburgk, 1841) & - & $\mathrm{X}$ & - \\
\hline Hyphessobrycon stegemanni Géry, 1961 & - & $\mathrm{X}$ & $83507,97954,98556,98606$ \\
\hline Hyphessobrycon sp. 1 "vermelhinho" & $(\mathrm{X})$ & $\mathrm{X}$ & 98514 \\
\hline Hyphessobrycon sp. 2 "garganta vermelha" & $(\mathrm{X})$ & $\mathrm{X}$ & 98515,98639 \\
\hline Hyphessobrycon sp. 3 "falsa Moenkhausia lepidura" & $(\mathrm{X})$ & - & 98530 \\
\hline Jupiaba polylepis (Günther, 1864) & - & $\mathrm{X}$ & 97946 \\
\hline Moenkhausia collettii (Steindachner, 1882) & - & $\mathrm{X}$ & 83492 \\
\hline Moenkhausia oligolepis ${ }^{4}$ (Günther, 1864) & - & $\mathrm{X}$ & 98609,75379 \\
\hline Moenkhausia tergimacula Lucena \& Lucena, 1999 & - & $\mathrm{X}$ & 97940,83493 \\
\hline Moenkhausia sp. & - & $\mathrm{X}$ & 97947 \\
\hline Poptella compressa (Günther, 1864) & - & $\mathrm{X}$ & 98559 \\
\hline Salminus sp. $* 5$ & - & $\mathrm{X}$ & - \\
\hline Tetragonopterus chalceus Spix \& Agassiz, 1829 & - & $\mathrm{X}$ & 83490,97933 \\
\hline \multicolumn{4}{|l|}{ Siluriformes } \\
\hline \multicolumn{4}{|l|}{ Loricariidae (5) } \\
\hline Spatuloricaria evansii (Boulenger, 1892) & - & $\mathrm{X}$ & 83520 \\
\hline Hypostomus sp. & - & $\mathrm{X}$ & 83515,83521 \\
\hline Hypostomus emarginatus (Valenciennes, 1840) & - & $\mathrm{X}$ & 83511 \\
\hline Hemiancistrus sp. & - & $\mathrm{X}$ & 83486 \\
\hline \multicolumn{4}{|l|}{ Auchenipteridae (1) } \\
\hline Trachelyopterus cf. galeatus (Linnaeus, 1766) & $(\mathrm{X})$ & $\mathrm{X}$ & 98537 \\
\hline \multicolumn{4}{|l|}{ Heptapteridae (1) } \\
\hline Pimelodella sp. & - & $\mathrm{X}$ & 97942 \\
\hline Rhamdia cf. quelen (Quoy \& Gaimard, 1824) & $(\mathrm{X})$ & $\mathrm{X}$ & 98536 \\
\hline \multicolumn{4}{|l|}{ Pimelodidae (1) } \\
\hline $\begin{array}{l}\text { Aguarunichthys tocantinsensis Zuanon, } \\
\text { Rapp Py-Daniel \& Jégu, } 1993\end{array}$ & - & $\mathrm{X}$ & 83526 \\
\hline
\end{tabular}


Tabela 4. Continuação...

Table 4. Continued...

\begin{tabular}{|c|c|c|c|}
\hline Espécies & $\begin{array}{c}\text { E.E. Serra } \\
\text { Geral do } \\
\text { Tocantins }\end{array}$ & Entorno & Lote-testemunho \\
\hline \multicolumn{4}{|l|}{ Gymnotiformes } \\
\hline \multicolumn{4}{|l|}{ Gymnotidae (2) } \\
\hline Electrophorus electricus* (Linnaeus, 1766) & - & $\mathrm{X}$ & - \\
\hline Gymnotus sp. & $(\mathrm{X})$ & $\mathrm{X}$ & 98519,98551 \\
\hline \multicolumn{4}{|l|}{ Sternopygidae (3) } \\
\hline Archolaemus blax Korringa, 1970 & - & $\mathrm{X}$ & 97943 \\
\hline Sternopygus macrurus (Bloch \& Schneider, 1801) & $(\mathrm{X})$ & $\mathrm{X}$ & 98547,98520 \\
\hline Eigenmannia sp. & $(\mathrm{X})$ & $\mathrm{X}$ & $97953,98545,83485,98518$ \\
\hline \multicolumn{4}{|l|}{ Rhamphichthyidae (1) } \\
\hline Gymnorhamphichthys rondoni (A. Miranda-Ribeiro, 1920) & - & $\mathrm{X}$ & 98605 \\
\hline \multicolumn{4}{|l|}{ Cyprinodontiformes } \\
\hline \multicolumn{4}{|l|}{ Rivulidae (2) } \\
\hline Rivulus zygonectes Myers, 1927 & - & $\mathrm{X}$ & $97936,98557,98604$ \\
\hline Rivulus sp. "Rio Novo" & $\mathrm{X}$ & - & 98490 \\
\hline \multicolumn{4}{|l|}{ Perciformes } \\
\hline \multicolumn{4}{|l|}{ Cichlidae (5) } \\
\hline Cichlasoma sanctifranciscense Kullander, 1983 & $\mathrm{X}$ & $\mathrm{X}$ & $83498,98571,98498,98521$ \\
\hline Crenicichla lugubris Heckel, 1840 & - & $\mathrm{X}$ & 83512 \\
\hline Crenicichla cf. inpa Ploeg, 1991 & $\mathrm{X}$ & $\mathrm{X}$ & $\begin{array}{c}98608,83523,83516,98554 \\
98495,98501,98511\end{array}$ \\
\hline Geophagus cf. altifrons ${ }^{6} \mathrm{Heckel,} 1840$ & - & $\mathrm{X}$ & 97936,83510 \\
\hline Retroculus lapidifer (Castelnau, 1855) & - & $\mathrm{X}$ & 83519,102951 \\
\hline
\end{tabular}

Tabela 5. Peixes registrados na bacia do Rio Sapão, no interior da E.E. Serra Geral do Tocantins e entorno. (X) - Baseado nos registros de Eigenmann (1921) e Haseman (1911) para a localidade "Rio Sapão, Prazeres". Lotes-testemunho estão catalogados na coleção do MZUSP.

Table 5. Fishes recorded at Rio Sapão basin, at the E.E. Serra Geral do Tocantins and surrounding areas. (X) - Species recorded by Eigenmann (1921) and Haseman (1911) for "Rio Sapão, Prazeres". Voucher lots are all cataloged at MZUSP.

\begin{tabular}{|c|c|c|c|}
\hline Espécies & $\begin{array}{c}\text { E.E. Serra } \\
\text { Geral do } \\
\text { Tocantins }\end{array}$ & Entorno & Lotes-testemunho \\
\hline \multicolumn{4}{|l|}{ Characiformes } \\
\hline \multicolumn{4}{|l|}{ Anostomidae (2) } \\
\hline Leporinus piau Fowler, 1941 & - & $\mathrm{X}$ & $58226,83835,83838$ \\
\hline Leporinus taeniatus Lütken, 1875 & - & $\mathrm{X}$ & 83878 \\
\hline \multicolumn{4}{|l|}{ Crenuchidae (2) } \\
\hline Characidium bahiense Almeida, 1971 & - & $\mathrm{X}$ & 58930,83823 \\
\hline Characidium cf. zebra Eigenmann, 1909 & - & $\mathrm{X}$ & $83822,84086.84087$ \\
\hline \multicolumn{4}{|l|}{ Erythrinidae (1) } \\
\hline Hoplerythrinus unitaeniatus (Agassiz, 1829) & $\mathrm{X}$ & $\mathrm{X}$ & \\
\hline Hoplias cf. malabaricus (Bloch, 1794) & - & $\mathrm{X}$ & $57396,83830,84071$ \\
\hline \multicolumn{4}{|l|}{ Serrasalmidae (2) } \\
\hline Metynnis sp & - & $\mathrm{X}$ & 83816 \\
\hline Myloplus micans (Lütken, 1875) & - & $\mathrm{X}$ & 104504 \\
\hline \multicolumn{4}{|l|}{ Characidae (16) } \\
\hline Acestrorhynchus britskii (Menezes, 1969) & - & $\mathrm{X}$ & 83828 \\
\hline Acestrorhynchus lacustris (Lütken, 1875) & - & $\mathrm{X}$ & $57172,57173,83820,84089$ \\
\hline
\end{tabular}


Tabela 5. Continuação...

Table 5. Continued...

\begin{tabular}{|c|c|c|c|}
\hline Espécies & $\begin{array}{c}\text { E.E. Serra } \\
\text { Geral do } \\
\text { Tocantins } \\
\end{array}$ & Entorno & Lotes-testemunho \\
\hline Astyanax fasciatus (Cuvier, 1819) & - & $\mathrm{X}$ & 84161 \\
\hline Astyanax novae Eigenmann, 1911 & $(\mathrm{X})$ & $\mathrm{X}$ & $57496,57503,83836,84083,89660,89661$ \\
\hline Astyanax sp. & - & $\mathrm{X}$ & $83821,84127,84166,89658,89659$ \\
\hline Bryconops sp. "falso affinis" & - & $\mathrm{X}$ & $57927,83837,84068,84074$ \\
\hline Hasemania nana (Lütken, 1875) & - & $\mathrm{X}$ & 84072 \\
\hline Hemigrammus brevis Ellis, 1911 & - & $\mathrm{X}$ & \\
\hline Hemigrammus marginatus Ellis, 1911 & - & $\mathrm{X}$ & 84077 \\
\hline Hemigrammus sp. 2 “Sapão” & $\mathrm{X}$ & - & 98531 \\
\hline Hyphessobrycon micropterus (Eigenmann, 1915) & - & $\mathrm{X}$ & 58425,83827 \\
\hline Moenkhausia sanctaefilomenae (Steindachner, 1907) & - & $\mathrm{X}$ & $58268,58269,83829,84069$ \\
\hline Orthospinus franciscensis (Eigenmann, 1914) & - & $\mathrm{X}$ & $58282,84080,84089$ \\
\hline Phenacogaster franciscoensis Eigenmann, 1911 & - & $\mathrm{X}$ & 83831,84076 \\
\hline Serrapinnus piaba (Lütken, 1875) & - & $\mathrm{X}$ & $58589,58797,84079$ \\
\hline \multicolumn{4}{|l|}{ Siluriformes } \\
\hline \multicolumn{4}{|l|}{ Callichthyidae (1) } \\
\hline Corydoras multimaculatus Steindachner, 1907 & - & $\mathrm{X}$ & 57404,83825 \\
\hline \multicolumn{4}{|l|}{ Loricariidae (2) } \\
\hline Hypostomus sp. & - & $\mathrm{X}$ & 84066 \\
\hline Hisonotus sp. & - & $\mathrm{X}$ & 83826,84081 \\
\hline \multicolumn{4}{|l|}{ Heptapteridae (3) } \\
\hline Pimelodella sp. & - & $\mathrm{X}$ & 83832,84075 \\
\hline Phenacorhamdia sp. & - & $\mathrm{X}$ & 84082 \\
\hline Cetopsorhamdia iheringi Schubart \& Gomes, 1959 & - & $\mathrm{X}$ & 84090 \\
\hline \multicolumn{4}{|l|}{ Pseudopimelodidae (1) } \\
\hline Cephalosilurus fowleri Haseman, 1911 & - & $\mathrm{X}$ & 84084 \\
\hline \multicolumn{4}{|l|}{ Gymnotiformes } \\
\hline \multicolumn{4}{|l|}{ Sternopygidae (2) } \\
\hline Sternopygus macrurus (Bloch \& Schneider, 1801) & - & $\mathrm{X}$ & 83839 \\
\hline Eigenmannia sp. & - & $\mathrm{X}$ & $57894,83819,84070$ \\
\hline \multicolumn{4}{|l|}{ Hypopomidae (1) } \\
\hline Brachyhypopomus sp. & - & $\mathrm{X}$ & 87147 \\
\hline \multicolumn{4}{|l|}{ Cyprinodontiformes } \\
\hline \multicolumn{4}{|l|}{ Rivulidae (1) } \\
\hline Rivulus cf. decoratus Costa, 1989 & $\mathrm{X}$ & - & 98532 \\
\hline \multicolumn{4}{|l|}{ Perciformes } \\
\hline \multicolumn{4}{|l|}{ Cichlidae (2) } \\
\hline Cichlasoma sanctifranciscense Kullander, 1983 & $(\mathrm{X})$ & $\mathrm{X}$ & $58282,58927,84085,83833$ \\
\hline Crenicichla lepidota Heckel, 1840 & - & $\mathrm{X}$ & 84229,84230 \\
\hline \multicolumn{4}{|l|}{ Synbranchiformes } \\
\hline \multicolumn{4}{|l|}{ Synbranchidae (1) } \\
\hline Synbranchus sp. & - & $\mathrm{X}$ & $58285,84091,83815$ \\
\hline
\end{tabular}


Lima, F.C.T. \& Caires, R.A.

Tabela 6. Lista geral das espécies de peixes encontrados na região da E.E. Serra Geral de Tocantins, discutidos ao longo do artigo. 1. Bacia do Rio Tocantins. 2. Bacia do Rio São Francisco.

Table 6. List of the fish species found in the region of the E.E. Serra Geral de Tocantins, which are discussed along the text. 1. Rio Tocantins basin. 2. Rio São Francisco basin.

\begin{tabular}{|c|c|c|}
\hline Espécies & 1 & 2 \\
\hline \multicolumn{3}{|l|}{ Chondrichthyes } \\
\hline \multicolumn{3}{|l|}{ Myliobatiformes } \\
\hline \multicolumn{3}{|l|}{ Potamotrygonidae (1) } \\
\hline Potamotrygon cf. histrix (Müller \& Henle, 1834) & $\mathrm{X}$ & - \\
\hline \multicolumn{3}{|l|}{ Characiformes } \\
\hline \multicolumn{3}{|l|}{ Anostomidae (6) } \\
\hline Leporinus bistriatus Britski, 1997 & $\mathrm{X}$ & - \\
\hline Leporinus ortomaculatus Garavello, 2000 & $\mathrm{X}$ & - \\
\hline Leporinus piau Fowler, 1941 & - & $\mathrm{X}$ \\
\hline Leporinus taeniatus Lütken, 1875 & - & $\mathrm{X}$ \\
\hline Leporinus tigrinus Borodin, 1929 & $\mathrm{X}$ & - \\
\hline Leporinus sp. & $\mathrm{X}$ & - \\
\hline \multicolumn{3}{|l|}{ Curimatidae (1) } \\
\hline Cyphocharax cf. spilurus Günther, 1864 & $\mathrm{X}$ & - \\
\hline \multicolumn{3}{|l|}{ Hemiodontidae (2) } \\
\hline Hemiodus ternetzi Myers, 1927 & $\mathrm{X}$ & - \\
\hline Hemiodus unimaculatus (Bloch, 1794) & $\mathrm{X}$ & - \\
\hline \multicolumn{3}{|l|}{ Crenuchidae (5) } \\
\hline Characidium bahiense Almeida, 1971 & - & $\mathrm{X}$ \\
\hline Characidium cf. zebra Eigenmann, 1909 & $\mathrm{X}$ & $\mathrm{X}$ \\
\hline Characidium sp. "linha lateral incompleta" & $\mathrm{X}$ & - \\
\hline Characidium sp. 2 "jobertina” & $\mathrm{X}$ & - \\
\hline Characidium sp. 3 "jobertina X xanthopterum" & $\mathrm{X}$ & - \\
\hline \multicolumn{3}{|l|}{ Ctenoluciidae (1) } \\
\hline Boulengerella cuvieri (Agassiz, 1829) & $\mathrm{X}$ & - \\
\hline \multicolumn{3}{|l|}{ Erythrinidae (3) } \\
\hline Hoplerythrinus unitaeniatus (Agassiz, 1829) & $\mathrm{X}$ & $\mathrm{X}$ \\
\hline Hoplias aimara (Valenciennes, 1847) & $\mathrm{X}$ & - \\
\hline Hoplias cf. malabaricus (Bloch, 1794) & $\mathrm{X}$ & $\mathrm{X}$ \\
\hline \multicolumn{3}{|l|}{ Serrasalmidae (6) } \\
\hline Acnodon normani Gosline, 1951 & $\mathrm{X}$ & - \\
\hline Metynnis sp. & - & $\mathrm{X}$ \\
\hline Mylesinus paucisquamatus Jégu \& Santos, 1988 & $\mathrm{X}$ & - \\
\hline Myleus setiger Müller \& Troschel, 1844 & $\mathrm{X}$ & - \\
\hline Myloplus micans (Lütken, 1875) & - & $\mathrm{X}$ \\
\hline Myloplus cf. torquatus (Kner, 1858) & $\mathrm{X}$ & - \\
\hline Characidae (45) & - & - \\
\hline Acestrocephalus acutus Menezes, 2006 & $\mathrm{X}$ & - \\
\hline Acestrocephalus stigmatus Menezes, 2006 & $\mathrm{X}$ & - \\
\hline Acestrorhynchus falcatus (Bloch, 1794) & $\mathrm{X}$ & - \\
\hline Acestrorhynchus lacustris (Lütken, 1875) & - & $\mathrm{X}$ \\
\hline Acestrorhynchus microlepis (Schomburgk, 1841) & $\mathrm{X}$ & \\
\hline Astyanax fasciatus (Cuvier, 1819) & - & $\mathrm{X}$ \\
\hline Astyanax novae Eigenmann, 1911 & $\mathrm{X}$ & $\mathrm{X}$ \\
\hline Astyanax sp. (grupo A. scabripinnis) & $\mathrm{X}$ & - \\
\hline Astyanax sp. & $\mathrm{X}$ & $\mathrm{X}$ \\
\hline Brycon sp. & $\mathrm{X}$ & - \\
\hline Bryconops alburnoides (Kner, 1859) & $\mathrm{X}$ & - \\
\hline Bryconops sp. 1 "Rio Novo"* & $\mathrm{X}$ & $\mathrm{X}$ \\
\hline
\end{tabular}


Tabela 6. Continuação...

Table 6. Continued...

\begin{tabular}{|c|c|c|}
\hline Espécies & 1 & 2 \\
\hline Bryconops sp. 2 "Rio Preto" & $X$ & - \\
\hline Bryconops sp. 3 "Frito Gordo" & $X$ & - \\
\hline Caiapobrycon tucurui Malabarba \& Vari, 2000 & $\mathrm{X}$ & - \\
\hline Creagrutus britskii Vari \& Harold, 2001 & $\mathrm{X}$ & - \\
\hline Creagrutus saxatilis Vari \& Harold, 2001 & $\mathrm{X}$ & - \\
\hline Knodus cf. savannensis Géry, 1961 & $\mathrm{X}$ & - \\
\hline Knodus sp. 1 "Rio Novo" & $\mathrm{X}$ & - \\
\hline Knodus sp. 2 & $\mathrm{X}$ & - \\
\hline Hasemania nana (Lütken, 1875) & - & $\mathrm{X}$ \\
\hline Hasemania sp. & $X$ & - \\
\hline Hemigrammus brevis Ellis, 1911 & - & $\mathrm{X}$ \\
\hline Hemigrammus marginatus Ellis, 1911 & - & $\mathrm{X}$ \\
\hline Hemigrammus sp. 1 "gorducho" & $\mathrm{X}$ & - \\
\hline Hemigrammus sp. 2 "Sapão" & - & $\mathrm{X}$ \\
\hline Hydrolycus armatus (Jardine \& Schomburgk, 1841) & $\mathrm{X}$ & - \\
\hline Hyphessobrycon micropterus (Eigenmann, 1915) & - & $\mathrm{X}$ \\
\hline Hyphessobrycon stegemanni Géry, 1961 & $\mathrm{X}$ & - \\
\hline Hyphessobrycon sp. 1 "vermelhinho" & $\mathrm{X}$ & - \\
\hline Hyphessobrycon sp. 2 "garganta vermelha” & $\mathrm{X}$ & - \\
\hline Hyphessobrycon sp. 3 "falsa Moenkhausia lepidura" & $\mathrm{X}$ & - \\
\hline Jupiaba polylepis (Günther, 1864) & $\mathrm{X}$ & - \\
\hline Moenkhausia collettii (Steindachner, 1882) & $\mathrm{X}$ & - \\
\hline Moenkhausia oligolepis (Günther, 1864) & $\mathrm{X}$ & - \\
\hline Moenkhausia sanctaefilomenae (Steindachner, 1907) & - & $\mathrm{X}$ \\
\hline Moenkhausia tergimacula Lucena \& Lucena, 1999 & $\mathrm{X}$ & - \\
\hline Moenkhausia sp. & $\mathrm{X}$ & - \\
\hline Orthospinus franciscensis (Eigenmann, 1914) & - & $\mathrm{X}$ \\
\hline Phenacogaster franciscoensis Eigenmann, 1911 & - & $\mathrm{X}$ \\
\hline Poptella compressa (Günther, 1864) & $\mathrm{X}$ & - \\
\hline Roeboexodon guyanensis (Puyo, 1948) & $\mathrm{X}$ & - \\
\hline Salminus sp. & $\mathrm{X}$ & - \\
\hline Serrapinnus piaba (Lütken, 1875) & - & $\mathrm{X}$ \\
\hline Tetragonopterus chalceus Spix \& Agassiz, 1829 & $\mathrm{X}$ & - \\
\hline \multicolumn{3}{|l|}{ Siluriformes } \\
\hline \multicolumn{3}{|l|}{ Trichomycteridae (2) } \\
\hline Ituglanis sp. & $\mathrm{X}$ & - \\
\hline Homodiaetus sp. & $\mathrm{X}$ & - \\
\hline \multicolumn{3}{|l|}{ Callichthyidae (2) } \\
\hline Aspidoras sp. & $\mathrm{X}$ & - \\
\hline Corydoras multimaculatus Steindachner, 1907 & - & $\mathrm{X}$ \\
\hline \multicolumn{3}{|l|}{ Loricariidae (8) } \\
\hline Hisonotus sp. & - & $\mathrm{X}$ \\
\hline Harttia punctata Rapp Py-Daniel \& Oliveira, 2001 & $\mathrm{X}$ & - \\
\hline Loricaria sp. & $\mathrm{X}$ & - \\
\hline Spatuloricaria evansii (Boulenger, 1892) & $\mathrm{X}$ & - \\
\hline Hypostomus sp. "Tocantins" & $\mathrm{X}$ & - \\
\hline Hypostomus sp. "São Francisco" & - & $\mathrm{X}$ \\
\hline Hypostomus emarginatus (Valenciennes, 1840) & $X$ & - \\
\hline Hemiancistrus sp. & $\mathrm{X}$ & - \\
\hline
\end{tabular}


Tabela 6. Continuação...

Table 6. Continued...

\begin{tabular}{|c|c|c|}
\hline Espécies & 1 & 2 \\
\hline \multicolumn{3}{|l|}{ Auchenipteridae (3) } \\
\hline Tatia sp. & $\mathrm{X}$ & - \\
\hline Centromochlus sp. & $\mathrm{X}$ & - \\
\hline Trachelyopterus cf. galeatus (Linnaeus, 1766) & $\mathrm{X}$ & - \\
\hline \multicolumn{3}{|l|}{ Heptapteridae (7) } \\
\hline Cetopsorhamdia sp. & $\mathrm{X}$ & - \\
\hline Cetopsorhamdia iheringi Schubart \& Gomes, 1959 & - & $\mathrm{X}$ \\
\hline Pimelodella sp. "São Francisco" & - & $\mathrm{X}$ \\
\hline Pimelodella sp. "Tocantins" & $\mathrm{X}$ & - \\
\hline Phenacorhamdia sp. "longa" & $\mathrm{X}$ & $\mathrm{X}$ \\
\hline Phenacorhamdia sp. "curta" & - & $\mathrm{X}$ \\
\hline Rhamdia cf. quelen (Quoy \& Gaimard, 1824) & $\mathrm{X}$ & - \\
\hline \multicolumn{3}{|l|}{ Pimelodidae (1) } \\
\hline Aguarunichthys tocantinsensis Zuanon, Rapp Py-Daniel \& Jégu, 1993 & $\mathrm{X}$ & - \\
\hline \multicolumn{3}{|l|}{ Pseudopimelodidae (1) } \\
\hline Cephalosilurus fowleri Haseman, 1911 & - & $\mathrm{X}$ \\
\hline \multicolumn{3}{|l|}{ Gymnotiformes } \\
\hline \multicolumn{3}{|l|}{ Gymnotidae (2) } \\
\hline Electrophorus electricus (Linnaeus, 1766) & $\mathrm{X}$ & - \\
\hline Gymnotus sp. & $\mathrm{X}$ & - \\
\hline \multicolumn{3}{|l|}{ Sternopygidae (3) } \\
\hline Archolaemus blax Korringa, 1970 & $\mathrm{X}$ & - \\
\hline Sternopygus macrurus (Bloch \& Schneider, 1801) & $\mathrm{X}$ & $\mathrm{X}$ \\
\hline Eigenmannia sp. & $\mathrm{X}$ & $\mathrm{X}$ \\
\hline \multicolumn{3}{|l|}{ Hypopomidae } \\
\hline Brachyhyроротиs sp. & - & $\mathrm{X}$ \\
\hline \multicolumn{3}{|l|}{ Rhamphichthyidae (1) } \\
\hline Gymnorhamphichthys rondoni (A. Miranda-Ribeiro, 1920) & $\mathrm{X}$ & - \\
\hline \multicolumn{3}{|l|}{ Cyprinodontiformes } \\
\hline \multicolumn{3}{|l|}{ Rivulidae (3) } \\
\hline Rivulus cf. decoratus Costa, 1989 & - & $\mathrm{X}$ \\
\hline Rivulus zygonectes Myers, 1927 & $\mathrm{X}$ & - \\
\hline Rivulus sp. "Rio Novo" & $\mathrm{X}$ & - \\
\hline \multicolumn{3}{|l|}{ Perciformes } \\
\hline \multicolumn{3}{|l|}{ Cichlidae (7) } \\
\hline Cichlasoma araguaiense Kullander, 1983 & $\mathrm{X}$ & - \\
\hline Cichlasoma sanctifranciscense Kullander, 1983 & $\mathrm{X}$ & $\mathrm{X}$ \\
\hline Crenicichla cf. inpa Ploeg, 1991 & $\mathrm{X}$ & - \\
\hline Crenicichla lepidota Heckel, 1840 & - & $\mathrm{x}$ \\
\hline Crenicichla lugubris Heckel, 1840 & $\mathrm{X}$ & - \\
\hline Geophagus cf. altifrons Heckel, 1840 & $\mathrm{X}$ & - \\
\hline Retroculus lapidifer (Castelnau, 1855) & $\mathrm{X}$ & - \\
\hline \multicolumn{3}{|l|}{ Synbranchiformes } \\
\hline \multicolumn{3}{|l|}{ Synbranchidae (1) } \\
\hline Synbranchus sp. & - & $\mathrm{X}$ \\
\hline Total & 85 spp. & $36 \mathrm{spp}$ \\
\hline
\end{tabular}


aos diferentes sistemas hidrográficos dentro da estação ecológica, combinados às circunstâncias pouco favoráveis à coleta, já que o período de amostragem se deu durante o pico da estação chuvosa. Contudo, esse baixo número indubitavelmente reflete também uma natural pobreza de espécies de peixes nos cursos d'água da E.E. Serra Geral do Tocantins, muito provavelmente devido ao fato de se tratar de uma região de cabeceiras, com rios e ribeirões de pequeno porte e isolados dos trechos de jusante por quedas d'água. Observações subaquáticas em vários pontos amostrados, como o córrego Piau (\#1), o Rio Cascavel (\# 3) e o Rio Novo (\# 4) não revelaram outras espécies além daquelas coletadas, embora, naturalmente, espécies noturnas e/ou crípticas eventualmente presentes nessas localidades podem não ter sido detectadas durante essas inspeções. De qualquer forma, como ressaltado nos itens anteriores, muita coleta adicional se fará necessária na E.E. Serra Geral do Tocantins, antes que sua ictiofauna possa ser considerada bem amostrada. $\mathrm{O}$ mesmo vale para a pequena porção da estação ecológica situada na bacia do Rio São Francisco na Bahia, cuja amostragem adequada foi impossibilitada durante a expedição devido ao elevado nível da água (ver acima, "Bacia do Rio Sapão", e apêndice 1).

A comparação entre as faunas de peixes da bacia do Rio Novo/do Sono/Balsas/Manuel Alves da Natividade (bacia do Rio Tocantins) e do Rio Sapão/rio Preto (bacia do Rio São Francisco) mostram que existe muito pouca similaridade ictiofaunística entre elas (Tabela 6). Das 111 espécies de peixes com ocorrência documentada para a região, $64(57,7 \%)$ são exclusivas da bacia do Rio Tocantins, 18 (16,2\%) são exclusivas da bacia do Rio São Francisco, e 25 (22,5\%) são espécies problemáticas, com taxonomia pouco resolvida, sobre as quais não é possível, no momento, confirmar se populações ocorrendo nas duas bacias são ou não co-específicas. Um exemplo deste último caso é Bryconops sp. "Rio Novo", que pode ser igual à espécie de Bryconops do Rio São Francisco, que tem sido há bastante tempo incorretamente identificada como sendo Bryconops affinis (Günther), uma espécie na verdade restrita às Guianas e que é claramente distinta (F.C.T. Lima, obs. pess.). Somente 5 espécies (4,5\%) ocorrem em ambos sistemas hidrográficos e parecem tratar-se de fato das mesmas espécies. Três delas - Hoplerythrinus unitaeniatus, Hoplias malabaricus e Sternopygus macrurus - são conhecidas por serem amplamente distribuídas pelas bacias hidrográficas da América do Sul cis-andina, e portanto não podem, a princípio, serem utilizadas como indicadoras de eventos de dispersão através do divisor de águas entre essas duas bacias (muito embora algumas, ou todas elas, tenham provavelmente suas populações conectadas em ambos os sistemas hidrográficos através dessa cabeceira comum). Apenas duas espécies podem ser no momento indubitalvemente indicadas como sendo compartilhadas entre as bacias dos rios Tocantins e São Francisco através da cabeceira comum entre os rios Sapão e Galheiros: o lambari Astyanax novae, que é somente conhecido da região próxima ao contato entre os dois sistemas hidrográficos (Eigenmann 1921, O.T. Oyakawa, com. pess.) e o acará Cichlasoma sanctifranciscense, referido acima. Esta última espécie é aqui citada pela primeira vez como ocorrendo na bacia do Rio Tocantins. Astyanax novae é endêmica das bacias dos rios do Sono e Manoel Alves da Natividade e do Rio Sapão, e portanto não oferece maiores pistas quanto à sua origem biogeográfica, exceto pelo fato de ser uma espécie endêmica da região das "águas emendadas". Por sua vez, Cichlasoma sanctifranciscense é uma espécie amplamente distribuída na bacia do Rio São Francisco e só conhecida no sistema do Tocantins na bacia do Rio do Sono, o que indica fortemente que a espécie colonizou esse trecho da bacia através das "águas emendadas" do Rio Sapão e do Rio Galheiros. Mais possíveis exemplos de espécies compartilhadas entre os dois sistemas através dessa cabeceira comum são espécies do gênero Hemigrammus (Characidae) e Rivulus (Rivulidae), já que representantes desses gêneros foram coletados na vereda do Sapão. Em ambos os casos, contudo, estudos taxonômicos detalhados são necessários para confirmar essa possibilidade. O presente estudo demonstra, portanto, que a cabeceira comum entre os rios do Sono e Sapão constitui uma conexão ictiofaunística muito pouco efetiva entre as bacias do Rio Tocantins e São Francisco, e que apenas algumas espécies de peixes de cabeceiras foram capazes de utilizar essa rota para atravessar o divisor de águas e colonizar a bacia vizinha.

Algumas espécies de peixes provavelmente ainda não descritas de peixes foram descobertas durante a expedição de fevereiro de 2008. São elas Hyphessobrycon sp. "vermelhinho" e Bryconops sp. "Frito Gordo" (Characidae), Characidium sp. "jobertina X xanthopterum" (Crenuchidae), Centromochlus sp. (Auchenipteridae) e Rivulus sp. "Rio Novo" (Rivulidae). Várias outras espécies coletadas são potencialmente novas para a ciência, mas estudos detalhados de revisão dos grupos aos quais elas pertencem são necessários para certificar essa possibilidade. Não é possível ainda afirmar que qualquer dessas potenciais espécies não descritas seja realmente endêmica da região. Como exemplo, outra espécie potencialmente nova coletada durante a expedição, Leporinus sp., já havia sido citada para o baixo Rio Tocantins (como Leporinus sp. 3: Santos et al. 1989), como também para outras localidades da bacia do Rio Tocantins (material depositado no MZUSP). Contudo, seu status taxonômico precisa ser avaliado adequadamente, sendo próxima de L. megalepis (J.L. Birindelli, com. pess.). Muito trabalho taxonômico e de coleta resta ainda a ser feito para tornar a ictiofauna da bacia do Rio Tocantins de fato bem conhecida, uma afirmação, aliás, válida para grande parte da fauna de peixes da grande maioria dos rios sul-americanos.

Duas espécies de peixes consideradas como ameaçadas de extinção foram registradas no Rio do Sono, na região a jusante da Cachoeira da Velha: o bagre Aguarunichthys tocantinsensis e o pacu Mylesinus paucisquamatus. Essas espécies são altamente reofílicas e ocorrem em ambientes de corredeiras de rios, com fundo pedregoso (Lima 2008, Jégu et al. 2008). Nessa localidade também foi coletado Archolaemus blax, um sarapó especializado em ambientes de corredeiras, relativamente incomum (Schwassmann \& Carvalho 1985). Das 16 espécies de peixes consideradas como ameaçadas de extinção na bacia do Rio Tocantins, nove são altamente reofílicas e ameaçadas pela destruição de seu hábitat em decorrência da construção de hidrelétricas (Rosa \& Lima, 2008). A ocorrência de Aguarunichthys tocantinsensis e Mylesinus paucisquamatus é um dado animador e, junto com a ocorrência de Archolaemus blax, indica que uma fauna de peixes altamente reofílicos ocorre no Rio do Sono, que potencialmente pode incluir mais espécies ameaçadas de extinção. Aguarunichthys tocantinsensis e Mylesinus paucisquamatus, contudo, não foram registradas na E.E. Serra Geral do Tocantins, e a ocorrência de tais espécies acima da Cachoeira da Velha é incerta (ver sob "Bacia do Rio Novo/do Sono").

Em conclusão, como já ressaltado acima, a fauna de peixes da E.E. Serra Geral do Tocantins, como de fato também do contíguo P.E. do Jalapão, permanece mal documentada, e mais coletas nessas duas unidades de conservação são necessárias para torná-las melhor conhecidas ictiologicamente. Ainda que os dados preliminares apontem uma baixa diversidade ictiofaunística na E.E. Serra Geral do Tocantins e na região do entorno da estação, há grande segregação e baixo intercâmbio de faunas entre as diferentes drenagens, sem dúvida um resultado da condição de cabeceiras dos cursos d'água a atravessarem a região. Embora seja difícil no momento julgar qual a importância relativa dessas duas unidades de conservação na preservação de peixes da bacia do Rio Tocantins, em grande parte porque muito ainda é ignorado sobre a ictiofauna dessa bacia, aparentemente existem espécies de peixes endêmicas às cabeceiras dos rios que drenam a região da E.E. Serra Geral do Tocantins, o 
que precisa ser confirmado mediante estudos adicionais. É, portanto, fortemente recomendada a continuação e a ampliação de estudos sobre a ictiofauna nessas unidades de conservação e em seu entorno. Esse fato, associado à presença de espécies de peixes ameaçados de extinção na região do entorno da E.E. Serra Geral do Tocantins e do P.E. do Jalapão, justifica que essa região de cabeceiras deve ser preservada de impactos antropogênicos adicionais, como construção de hidrelétricas e, principalmente, da pretendida transposição de águas da bacia do Rio Tocantins para o São Francisco, que, caso seja efetuada, resultará numa catastrófica mistura de duas ictiofaunas muito distintas.

\section{Agradecimentos}

Os autores são particularmente gratos a Cristiano Nogueira, pelo convite inicial para participar da expedição à E.E. Serra Geral do Tocantins e pela sua participação nas coletas de peixes, bem como pela leitura crítica do manuscrito e pela elaboração da Figura 1. Ana P. Carmignotto e Paula H. Valdujo também colaboraram com a coleta de alguns peixes durante a expedição. Osvaldo T. Oyakawa e José L. Birindelli forneceram informações sobre algumas espécies de peixes da bacia do Rio Tocantins. Através do exame de fotografias, Sven Kullander confirmou a identificação de Cichlasoma sanctifranciscense da bacia do Rio do Sono. Os autores são financiados pela FAPESP (FCTL: \# 07/02978-7) e CNPq (RAC: \# 140053/2008-5).

\section{Referências Bibliográficas}

ALOÍSIO, G.R., OLIVEIRA, F.G. \& ANGELINI, R. 2005. Fish, State Park of Jalapão, State of Tocantins, Brazil. Check. List. 1(1):10-13.

ALVES, C.B.M. \& POMPEU, P.S. 2001. A fauna de peixes da bacia do Rio das Velhas no final do século XX. In Peixes do Rio das Velhas: passado e presente. (C.B.M Alves \& P.S. Pompeu, orgs.). SEGRAC, Belo Horizonte, p. 165-187.

BARTHEM, R.B. \& SCHWASSMANN, H.O. 1994. Amazon river influence on the seasonal displacement of the salt wedge in the Tocantins river estuary, Brazil, 1983-1985. Bol. Mus. Para. Emilio Goeldi, 10(1):119-130.

BRITSKI, H.A., SATO, Y. \& ROSA, A.B.S. 1984. Manual de identificação de peixes da região de Três Marias. Câmara dos Deputados/CODEVASF, Brasília, $115 \mathrm{p}$.

BRITTO, M.R. \& CASTRO, R.M.C. 2002. New corydoradine catfish (Siluriformes: Callichthyidae) from the Upper Paraná and São Francisco: the sister group of Brochis and most of Corydoras species. Copeia (4):1006-1015. doi:10.1643/0045-8511(2002)002[1006:NCCSCF]2.0 . $\mathrm{CO} ; 2$

COSTA, W.J.E.M. 2001. The neotropical annual fish genus Cynolebias (Cyprinodontiformes: Rivulidae): phylogenetic relationships, taxonomic revision and biogeography. Ichthyol. Explor. Freshw. 12(4):333-383.

COSTA, W.J.E.M. 2003. The Simpsonichthys flavicaudatus species-group (Cyprinodontiformes: Rivulidae: Cynolebiatinae): phylogenetic relationships, taxonomic revision and biogeography. Ichthyol. Explor. Freshw. 14(1):31-60.

DE PINNA, M.C.C. 1998. Phylogenetic relationships of Neotropical Siluriformes (Teleostei: Ostariophysi): historical overview and synthesis of hypothesis. Pp. 279-330 In L.R. Malabarba, R.E. Reis, R.P. Vari, Z.M. Lucena \& C.A.S. Lucena (eds.), Phylogeny and classification of Neotropical freshwater fishes. Edipucrs, Porto Alegre.

EIGENMANN, C.H. 1917. The American Characidae [Part I]. Mem. Mus. Comp. Zoo. 43(1):1-102, prs 1-8, 12, 14-16, 95, 98, 100-101.

EIGENMANN, C.H. 1921. The American Characidae [Part III]. Mem. Mus. Comp. Zoo. 43(3):209-310, 28 prs.

EIGENMANN, C.H. 1927. The American Characidae [Part IV]. Mem. Mus. Comp. Zoo. 43(4):311-428, 24 pls.
FINK, W.L. 1993. Revision of the piranha genus Pygocentrus (Teleostei, Characiformes). Copeia (3): 665-687. doi:10.2307/1447228

HASEMAN, J.D. 1911. An annotated catalog of the cichlid fishes collected by the expedition of the Carnegie Museum to central South America, 1907-1910. Ann. Carnegie Mus. 7:329-373.

HASEMAN, J.D. \& EIGENMANN, C.H. 1911. A brief report upon the expedition of the Carnegie Museum to Central South America, together with a list of localities at which Mr. Haseman collected. Ann. Carnegie Mus. 7:287-314.

HUBERT, N., DUPONCHELLE, F., NUÑEZ, J., GARCIA-DAVILA, C., PAUGY, D. \& RENNO, J.-F. 2007. Phylogeography of the piranha genera Serrasalmus and Pygocentrus: implications for the diversification of the Neotropical ichthyofauna. Mol. Ecol. 16(10):2115-2136. doi:10.1111/ j.1365-294X.2007.03267.x PMid:17498236

GOULDing, M., BARTHEM, R. \& FERREIRA, E.J.G. 2003. The Smithsonian Atlas of the Amazon. Smithsonian Books, Washington, $253 \mathrm{p}$.

JÉGU, M., ALBRECHT, M.P. \& SANTOS, G.M. 2008. Mylesinus paucisquamatus Jégu \& Santos, 1988. In (A.B.M. Machado, G.M. Drummond \& A.P. Paglia, eds.). Livro vermelho da fauna brasileira ameaçada de extinção. Ministério do Meio Ambiente/Fundação Biodiversitas, Brasília, p. 82-83

KULLANDER, S.O. 1983. Revision of the South America cichlid genus Cichlasoma. Swedish Museum of Natural History, Estocolmo, 296 pp.

LANGEANI, F. 1990. Revisão do gênero Neoplecostomus Eigenmann \& Eigenmann, 1888, com a descrição de quatro novas espécies do sudeste Brasileiro (Ostariophysi, Siluriformes, Loricariidae). Comun. Mus. Cienc. PUCRS, Ser. Zool. 3(1):3-31.

LIMA, F.C.T. 2006. Revisão taxonômica e relações filogenéticas do gênero Salminus (Teleostei: Ostariophysi: Characiformes: Characidae). Tese de doutorado, Instituto de Biociências, Universidade de São Paulo, São Paulo.

LIMA, F.C.T. 2008. Aguarunichthys tocantinsensis Zuanon, Rapp Py-Daniel \& Jégu, 1993. In Livro vermelho da fauna brasileira ameaçada de extinção. (A.B.M. Machado, G.M. Drummond \& A.P. Paglia, eds.). Ministério do Meio Ambiente/Fundação Biodiversitas, Brasília, p. 225-226.

LIMA, F.C.T. \& RIBEIRO, A.C. 2011. Continental-scale tectonic controls of biogeography and ecology. In Historical Biogeography of Neotropical Freshwater Fishes. (J.S. Albert \& R.E. Reis, eds.). University of California Press.

LÜTKEN, C.F. 1875. Velha-Flodens Fiske. Et Bidrag til Brasiliens Ichthyologi; efter Professor J. Reinhardts Indsamlinger og Optegnelser. Kon. Dank. Vidensk. Selsk. Skrift. (Raekke) 12(2):121-253.

LÜTKEN, C.F. 2001. Peixes do Rio das Velhas: uma contribuição para a ictiologia do Brasil, de acordo com as coleções e descrições do Professor Johannes Theodor Reinhardt. In Peixes do Rio das Velhas: passado e presente. (Alves, C.B.M. \& P.S. Pompeu, orgs.). SEGRAC, Belo Horizonte, p. 23-164.

MENEZES, N.A. 1976. On the Cynopotaminae, a new subfamily of Characidae (Osteichthyes, Ostariophysi, Characoidei). Arq. Zool. 28(2):91.

MENEZES, N.A. 1987. Três espécies novas de Oligosarcus Günther, 1864 e redefinição taxonômica das demais espécies do gênero (Osteichthyes, Teleostei, Characidae). Bol. Zool. 11:1-39.

MENEZES, N.A. 1988. Implications of the distribution patterns of the species of Oligosarcus (Teleostei, Characidae) from Central and southern South America. In Proceedings of a workshop on neotropical distribution patterns. (W.R. Heyer \& P.E. Vanzolini, eds.). Academia Brasileira de Ciências, Rio de Janeiro. p. 295-304

MENEZES, N.A. 2007. Charax goeldii Fowler, 1913 a valid species of Galeocharax Fowler (Characiformes: Characidae). Neotrop. Ichthyol. 5(1):21-24.

PEREIRA, E.H.L. \& REIS, R.E. 2002. Revision of the loricariid genera Hemipsilichthys and Isbrueckerichthys (Teleostei: Siluriformes), with descriptions of five new species of Hemipsilichthys. Ichthyol. Explor. Freshw. 13(2):97-146. 
RIBEIRO, A. C. 2006. Tectonic history and the biogeography of the freshwater fishes from the coastal drainages of eastern Brazil: an example of faunal evolution associated with a divergent continental margin. Neotrop. Ichthyol. 4(2):225-246.

ROSA, R.S. \& LIMA, F.C.T. 2008. Os peixes ameaçados de extinção. In Livro vermelho da fauna brasileira ameaçada de extinção. (A.B.M. Machado, G.M. Drummond \& A.P. Paglia, eds.). Ministério do Meio Ambiente/ Fundação Biodiversitas, Brasília, p. 9-285.

SANTOS, G.M., JÉGU, M. \& de MÉRONA, B. 1984. Catálogo de peixes comerciais do baixo Rio Tocantins. Eletronorte/CNPq/INPA, Manaus, 83 p.

SANTOS, G.M., DE MÉRONA, B., JURAS, A.A. \& JÉGU, M. 2004. Peixes do baixo Rio Tocantins: 20 anos depois da Usina Hidrelétrica Tucuruí. Eletronorte, Brasília, 215 p.

SATO, Y. \& GODINHO, H. P. 1999. Peixes da bacia do Rio São Francisco. In Estudos ecológicos de comunidades de peixes tropicais. (R.H. LoweMcConnel). Edusp, São Paulo, p. 401-413.
SCHWASSMANN, H.O. \& CARVALHO, M.L. 1985. Archolaemus blax Korringa (Pisces, Gymnotiformes, Sternopygidae); a redescription with notes on ecology. Spixiana 8(3): 231-240.

VARI, R.P. 1988. The Curimatidae, a lowland Neotropical fish family (Pisces: Characiformes); distribution, endemism, and phylogenetic biogeography. In Proceedings of a Workshop on Neotropical Distribution Patterns. (P.E. Vanzolini and W.R. Heyer, eds.). Academia Brasileira de Ciências, Rio de Janeiro. p. 343-377

VARI, R.P., FERRARIS JUNIOR, C.J., \& DE PINNA, M.C.C. 2005. The Neotropical whale catfishes (Siluriformes: Cetopsidae: Cetopsinae), a revisionary study. Neotrop. Ichthyol. 3(2):127-238.

WINEMILLER, K.O., LÓPEZ-FERNÁNDEZ, H., TAPHORN, D.C., NICO, L.G. \& DUQUE, A. B. 2008. Fish assemblages of the Casiquiare River, a corridor and zoogeographical filter for dispersal between the Orinoco and Amazon basins. J. Biogeogr. 35:1551-1563. doi:10.1111/j.13652699.2008.01917.x 
Apêndice 1. Localidades amostradas na E.E. Serra Geral do Tocantins e arredores.

Interior da EESGT:

\# 1. Rio da Conceição, córrego Piau (bacia do Rio Balsas) [vereda do pitfall], E.E. Serra Geral do Tocantins, $11^{\circ} 12^{\prime} 26^{\prime}$ 'S, $46^{\circ} 53$ ' $41^{\prime \prime}$ 'W, $26-27 / 1 / 2008$.

Córrego pequeno (1-2 $\mathrm{m}$ de largura), profundidade entre 0,5-2 $\mathrm{m}$ de profundidade. Correnteza forte, fundo arenoso, água transparente e fria. Coletas realizadas ca. $500 \mathrm{~m}$ abaixo das nascentes. Campo úmido e veredas. Apenas três espécies de peixes coletadas. Alta densidade de Knodus cf. savannensis nas porções de poços mais fundos, observados durante mergulho. Rivulus zygonectes em poças rasas adjacentes ao córrego; Hoplerythrinus unitaeniatus coletados no campo úmido (capturados, após chuvas pesadas que alagaram o campo úmido, em armadilhas Sherman).

\# 2. Rio da Conceição, cabeceira do Rio das Balsas [córrego dos caçadores], E.E. Serra Geral do Tocantins, $11^{\circ} 5^{\prime} 58^{\prime}$ 'S, 46 $46^{\prime} 7^{\prime}$ 'W, 26/1/2008.

Ribeirão pequeno (1-1,5 m de largura), profundidade 0,3-1 $\mathrm{m}$. Correnteza moderada, fundo arenoso/siltoso, seixos em alguns trechos, um trecho cortando um afloramento de arenito. Água com algum sedimento em suspensão. Mata ciliar estreita e perturbada. Cinco espécies coletadas (Centromochlus sp., Knodus cf. savannensis, Phenacorhamdia sp. "curta", Phenacorhamdia sp. "longa" e Rivulus zygonectes), todas no próprio ribeirão.

\# 3. Rio da Conceição, Rio Cascavel, E.E. Serra Geral do Tocantins, $11^{\circ} 14$ '38'’'S, 46²48'45'’W; 27-28/1/2008.

Rio pequeno (4-5 m de largura, 1-2 m de profundidade). Águas cor de chá, mas ainda assim de elevada transparência. Correnteza forte e mata ciliar degradada. Fundo predominantemente arenoso, com bancos de macrófitas aquáticas em porções laterais do canal. Densidade de peixes muito baixa, evidenciada durante mergulho; apenas cinco espécies - Eigenmannia sp., Characidium sp. "linha lateral incompleta", Caiapobrycon tucurui, Creagrutus britskii e Hemigrammus sp. "gorducho" coletadas, todas em pequeno número. Hemigrammus sp. "gorducho" em grande parte parasitados por um Isopoda alojado na abertura urogenital, de onde o apelido.

\# 4. Mateiros, Rio Novo, perto da foz do córrego Lajeiro, E.E. Serra Geral do Tocantins [barraco do Manelão], 1046'23' 'S, 4643' 8', W; $1 / 2 / 2008$.

Rio grande (ca. $20 \mathrm{~m}$ de largura). Área marginal amostrada com 0,5-1,5 m de profundidade. Fundo rochoso, com rochas e matacões, imediatamente abaixo de um pequeno salto do rio. Mata ciliar quase inexistente, campo cerrado chegando à margem. Água clara, com elevada transparência. Coleta em grande parte realizada com puçás, durante mergulho. Todas as espécies observadas em mergulhos foram coletadas. Densidade de peixes relativamente alta; 9 espécies coletadas - Astyanax novae, Bryconops sp. "Rio Novo", Leporinus sp., Hasemania sp., Crenicichla cf. inpai, Characidium cf. zebra, Knodus sp. 1 "Rio Novo", Cichlasoma sanctifranciscense e Rivulus sp. "Novo", o último apenas em uma poça de água quente e escura, numa escavação natural do lajedo lateral ao rio.

\# 5. Mateiros, Rio Preto, limite norte da E.E. Serra Geral do Tocantins, próximo à região das dunas, 10³8'40' 'S, 4641'2' 'W; 1/2/2008,

Rio grande (c. $10 \mathrm{~m}$ de largura). Área marginal amostrada com 0.5-1,5 m de profundidade, fundo arenoso. Água cor de chá e com correnteza moderada. Mata ciliar muito estreita, com buritis; campo úmido amplo ao longo do vale do rio. Nove espécies coletadas: Knodus sp. Rio Novo", Bryconops sp. 'Rio Preto" (mais claro que Bryconops sp. "Rio Novo", mas isso pode ser variação geográfica); Crenicichla cf. inpai, Characidium cf. zebra, Characidium sp. "jobertina”, Astyanax novae, Acestrorhynchus falcatus, Leporinus sp. e Hasemania sp.

\# 6. Mateiros, Ribeirão Frito Gordo, afl. Rio Novo, limite norte da E.E. Serra Geral do Tocantins, 10³0'57' 'S, 4652' 46'’ W, 2//2/2008.

Ribeirão médio (4-5 m de largura, 0,5-2 m de profundidade). Águas claras, fundo arenoso/siltoso, áreas mais rasas com bancos de macrófitas. Correnteza relativamente forte. Seis espécies amostradas, Astyanax novae, Knodus sp. Rio Novo",

Hasemania sp., Crenicichla cf. inpai, Characidium cf. zebra e Bryconops sp. "Frito Gordo" (claramente distinto em colorido das espécies, ou espécie, do Rio Novo e Rio Preto).

\# 7. Bahia, Formosa do Rio Preto, vereda do Rio Sapão, E.E. Serra Geral do Tocantins, $10^{\circ} 44^{\prime} 41^{\prime}$ 'S, 46 11 ' $45^{\prime \prime}$ 'W, 3/2/2008.

Ampla vereda, ca. $300 \mathrm{~m}$ de largura no trecho visitado (que é um dos pontos mais estreitos, daí ter sido escolhido como local de construção do aterro da estrada). Inundada e aproximadamente $1 \mathrm{~m}$ acima do nível normal (avaliação feita tomando a vegetação terrestre submersa como referência). As coletas foram virtualmente impossibilitadas pela enchente, umas poucas piabinhas (Hemigrammus sp. "Sapão") capturadas com puçá, um Rivulus cf. decoratus apanhado na beira do alagado, e alguns Hoplerythrinus unitaeniatus avistados, mas não coletados. No dizer do caboclo: "água nova não tem peixe".

Entorno da EESGT:

\# 8. Rio da Conceição, córrego afluente do Rio Peixinho, perto do limite sul da E.E. Serra Geral do Tocantins [córrego podre], $11^{\circ} 18^{\prime} 49^{\prime}$ 'S, $46^{\circ} 56^{\prime} 15^{\prime \prime} \mathrm{W} ; 27 / 1 / 2008$.

Córrego pequeno (largura média $1 \mathrm{~m}$ ), correndo no interior de uma densa vereda de buritis. Ambiente aparentemente eutrofizado, água mal cheirosa. Apenas duas espécies de peixes coletados (Rivulus zygonectes e Eigenmannia sp.).

\# 9. Rio da Conceição, entorno da E.E. Serra Geral do Tocantins, Lagoa Bonita, perto do Rio Manuel Alves da Natividade, $11^{\circ} 18^{\prime} 51^{\prime}$ 'S, $46^{\circ} 42^{\prime} 31$ '’W; 29/1/2008.

Pequeno lago natural (300 m de comprimento), de águas transparentes, profundidade entre 0,3-2,00 m, com fundo arenoso (vegetação subaquática densa em alguns trechos marginais). Uma pequena cabeceira tributária ao alto Rio Manuel Alves da Natividade, formada talvez por algum processo de deflação erosiva (solo arenoso). Apenas duas espécies de peixes (Astyanax sp. e Characidium sp. "linha lateral incompleta") coletados, mas iúiú (Hoplerythrinus unitaeniatus) e traíra (Hoplias malabaricus) também ocorrem na lagoa, segundo moradores.

\# 10. Rio da Conceição, Rio Manuel Alves da Natividade, entorno da E.E. Serra Geral do Tocantins, perto da Lagoa Bonita, $11^{\circ} 16$ '46 'S, 4642'49',W; 29/1/2008.

Rio Manuel Alves da Natividade, próximo à sua cabeceira. Nesse trecho o Rio apresenta uma largura aproximada de 5-7 m, fundo arenoso, correnteza moderada a forte, e corre dentro de uma mata ciliar estreita. Apenas quatro espécies de peixes coletadas (Knodus cf. savannensis, Creagrutus britskii, Phenacorhamdia sp. "curta" e Characidium sp. "linha lateral incompleta").

\# 11. Rio da Conceição, Rio Manuel Alves da Natividade, entorno da E.E. Serra Geral do Tocantins, perto da cabeceira, $11^{\circ} 15^{\prime} 39^{\prime}$ 'S, 46³9'30''W; 29/1/2008. 
Rio Manuel Alves da Natividade, muito próximo à sua cabeceira, onde ele é praticamente um ribeirão. Apresenta nesse trecho uma largura de 5-6 m, fundo rochoso, correnteza rápida. Vegetação marginal composta por densa mata ciliar. Apenas duas espécies, Creagrutus britskii e Knodus cf. savannensis, coletadas.

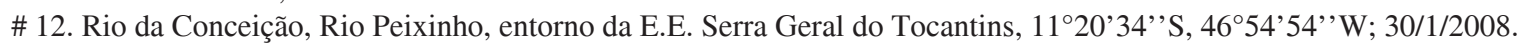

O Rio Peixinho é nesse trecho ainda um Rio pequeno, com aproximadamente 6 metros de largura, porém profundo ( $>2 \mathrm{~m}$, exceto em algumas áreas marginais). Vegetação subaquática abundante, água com elevada transparência e com alta velocidade. Apenas duas espécies (Hemigrammus sp. "gorducho" e Characidium sp. "linha lateral interrompida") coletados.

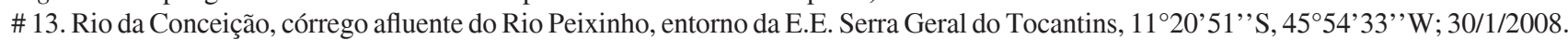

Córrego de primeira ordem, correndo em vereda crescendo em campo úmido. Água transparente, fria. Maioria do córrego escondida sob o campo úmido, apenas uma área exposta, num caminho de boi. Apenas duas espécies coletadas (Rivulus zygonectes e Hemigrammus sp. "gorducho").

\# 14. Rio da Conceição, córrego Mumbuca, afluente do Peixinho, perto da cidade, entorno da E.E. Serra Geral do Tocantins (estrada para o Rio Peixinho), $11^{\circ} 21^{\prime} 42^{\prime}$ 'S, 4654'35' 'W; 30/1/2008.

Ribeirão de águas transparentes, com fundo arenoso/pedregoso, com aproximadamente $3 \mathrm{~m}$ de largura, profundidade em geral não excedendo 0.8 m. Coleta e observação subaquática só revelaram duas espécies de peixes, Hemigrammus sp. "gorducho" e Aspidoras sp.

\# 15. Mateiros, ribeirão Brejão, afluente do Rio Preto, entorno da E.E. Serra Geral do Tocantins próximo ao limite N da EESGT, próximo da sede do Parque Estadual do Jalapão, 10³4'29' 'S, 46²9'12', W; 1-3/2/2008.

Ribeirão de águas claras, com fundo arenoso, correndo em floresta ciliar com buritis. Áreas alagadas com densa vegetação subaquática adjacentes ao canal do ribeirão. Ponto com maior riqueza em espécies, com 12 espécies registradas: Hyphessobrycon sp. "vermelhinho", Hyphessobrycon sp. "garganta vermelha", Astyanax novae, Knodus sp. "Rio Novo", Eigenmannia sp., Gymnotus sp., Sternopygus macrurus, Cichlasoma sanctifranciscense, Characidium sp. "xanthopterum X jobertina", Bryconops sp. "Rio Preto", Hoplias cf. malabaricus e Characidium cf. zebra.

\# 16. Mateiros, Rio Novo, abaixo da ponte, perto da antiga casa do seu Lilio, entorno da E.E. Serra Geral do Tocantins, $10^{\circ} 33^{\prime} 11^{\prime}$ 'S, $46^{\circ} 45^{\prime} 37^{\prime}$ 'W; 2/2/2008.

Rio grande (c. 20 m de largura), com águas claras e fundo pedregoso. Por ocasião da coleta, após uma chuva pesada, o Rio Novo encontrava-se com nível das águas bastante alto. Apenas cinco espécies coletadas, Knodus sp. "Rio Novo", Astyanax novae, Characidium cf. zebra, Bryconops sp. "Rio Novo" e Hyphessobrycon sp. "falsa Moenkhausia lepidura".

\# 17. Mateiros, Rio Galhão, Pousada Rio Galhão, Entorno da EE Serra Geral do Tocantins, 10³6'23'’S, 46¹4’36'’W 11-14/2/2008.

Rio pequeno (4 m de largura), porém fundo e com forte correnteza. Arrasto em áreas rasas, alguns bagres pescados com anzol. Cinco espécies coletadas: Astyanax novae, Bryconops sp. "Rio Preto", Knodus sp. "Rio Novo", Rhamdia cf. quelen e Trachelyopterus cf. galeatus. 
Apêndice 2. Material do gênero Cichlasoma (Cichlidae) examinado.

Cichlasoma sanctifranciscense: Bacia do Rio São Francisco: MZUSP 84085 (9, 13,1-84,0 mm CP): Bahia, Formosa do Rio Preto, Brejão, Rio Sapão, à oeste do povoado de São Marcelo, 1055'39' 'S, 4541'54' 'W; C.R. Moreira \& J.C. Nolasco, 6 Agosto 2002. MZUSP 84043 (7, 30,2-64,5 mm CP): Bahia, Formosa do Rio Preto, Rio Preto, povoado de Cacimbinhas, pela estrada da garganta (Diánopolis - Formosa do Rio Preto), $11^{\circ} 8^{\prime} 28^{\prime}$ 'S, 46²' 1' W; C.R. Moreira \& J.C. Nolasco, 3 Agosto 2002. Bacia do Rio Tocantins: MZUSP 98571 (12, $24,6-69,6$ mm CP): Tocantins, Mateiros, vereda na estrada para a Cachoeira da Velha, 10¹8'56' 'S, 4657'47' 'W; O.T. Oyakawa, A. Akama, V. Garutti \& J.C. Nolasco, 1 Abril 2001. MZUSP 83498 (1, 50,2 mm CP): Mateiros, Lagoa das Dunas (riacho da Areia), P.E. do Jalapão, 10³4’5' 'S, 46³9'50'’W; G. Aloísio et al., 16 Julho 2003. MZUSP 98521 (5, 15,5-73,1 mm CP): Mateiros, córrego Brejão (afl. Rio Preto), próximo à sede do P.E. do Jalapão, 10³4'29' 'S, 46²9' 12'’W; F.C.T. Lima, R.A. Caíres \& C. Nogueira, 3 Fevereiro 2008. MZUSP 98498 (2, 57,6-63,2 mm CP): Mateiros, Rio Novo, perto da foz do córrego Lajeiro, E.E. Serra Geral do Tocantins, 1046'23' 'S, 4643' 8' 'W; F.C.T. Lima, R.A. Caíres \& C. Nogueira, 1 Fevereiro 2008.

Cichlasoma araguaiense: MZUSP 81669 (1, 96,8 mm CP): Goiás, São Domingos, Rio Angélica, Lapa da Angélica, P.E. de Terra Ronca; F.C.T. Lima, M.E. Bichuette \& E. Trajano, 20 Maio 1999. MZUSP 53979 (1, 55,3 mm CP): Goiás, Minaçú, córrego da Água Parada, afluente do Rio do Peixe, $14^{\circ} 17^{\prime}$ S, $48^{\circ} 55^{\prime}$ W; M.T. Rodrigues et al., Maio 1996. MZUSP 84054 (1, 37,7 mm CP): Tocantins, Rio da Conceição, Rio

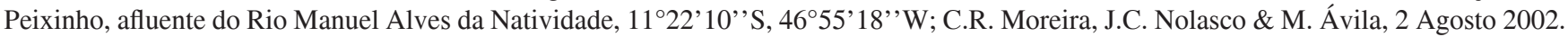
MZUSP 52189 (13, 40,3-72,9 mm CP): Tocantins, Araguaçu, Rio Água Fria (afl. Rio Araguaia), fazenda Praia Alta 2, 1244’S, 4956’W; F.C.T. Lima, A.N. Furlani, L.S. Rocha \& A. Aleixo, 8 Julho 1997. 